\title{
Identification and modelling of applicable wear conditions for stir cast Al-composite
}

\author{
Santanu SARDAR ${ }^{1}$, Santanu Kumar KARMAKAR ${ }^{1}$, Debdulal DAS ${ }^{2, *}$ \\ ${ }^{1}$ Department of Mechanical Engineering, Indian Institute of Engineering Science and Technology, Howrah 711103, India \\ ${ }^{2}$ Department of Metallurgy and Materials Engineering, Indian Institute of Engineering Science and Technology, Howrah 711103, India \\ Received: 07 July 2018 / Revised: 08 February 2019 / Accepted: 11 May 2019 \\ (C) The author(s) 2019.
}

\begin{abstract}
A comprehensive study of the tribological performance of the $\mathrm{Al}-\mathrm{Zn}-\mathrm{Mg}-\mathrm{Cu} / \mathrm{Al}_{2} \mathrm{O}_{3}$ composite and its matrix alloy is presented in this paper, with a specific emphasis to identify and model the applicable wear conditions where the composite provides a minimum of $50 \%$ reduction in wear rate and $25 \%$ lowering of the friction coefficient. Two-body abrasion experiments following Taguchi $\mathrm{L}_{27}$ orthogonal design have been performed separately on alloy and composite materials, both prepared by the stir casting method. The influence of crucial control factors including silicon carbide $(\mathrm{SiC})$ abrasive size, load, sliding distance, and velocity on the percentage variations of wear rates and friction coefficients between alloy and composite have been studied using the analysis of variance technique and full quadratic regression method. The dominant control factors are identified as abrasive size, load, and the interaction between abrasive size and load. This has been verified by establishing the influence of abrasive size and load on variations of wear mechanisms like microcutting, microploughing, and delamination, identified by means of in-depth characterization of worn surfaces and generated debris for both alloy and composite. The selection of applicable tribological condition for the composite has been accomplished by adopting the multi-response optimization technique based on combined desirability approach to obtain concurrent optimization of the percentage variations of wear rates and friction coefficients. Predictive models correlating the superiority of tribological performance of composite with abrasion conditions have been developed, and these are found to be accurate (errors $<10 \%$ ), as determined by confirmatory experiment.
\end{abstract}

Keywords: aluminum matrix composite; tribology; design of experiment; Taguchi; multi-response optimization; abrasion mechanism

\section{Introduction}

The urge to reduce greenhouse gas emissions and the ever-increasing cost of fossil fuel have led towards the development of weight-saving components for aerospace and automotive industries, where aluminum and its alloys are favored because of their higher strength-to-weight ratio [1, 2]. However, the relatively poor wear resistance property of aluminum alloys limits their applications in tribological fields [3, 4], which paves the way for exploring discontinuous ceramic reinforced aluminum matrix composites (AMCs) because of their excellent wear and corrosion resistance abilities in addition to improved mechanical properties over unreinforced $\mathrm{Al}$ alloys [5]. The enhanced wear resistance of AMCs is attributed to the embedded hard ceramic reinforcements which act as principle load carrying elements and thus protect the soft metallic surface from wear [6, 7]. Among all $\mathrm{Al}$ series alloys, 7xxx series alloys, such as the Al 7075 (Al-Zn-Mg-Cu) alloy have been commonly preferred because of the high strength-to-weight ratio in addition to other qualities like improved fatigue resistance, fracture toughness, and compressive strength [8]. The Al 7075

* Corresponding author: Debdulal DAS, E-mail: debdulal_das@metal.iiests.ac.in 
alloy is widely employed in aircraft structural components (e.g., wings, horizontal, and vertical stabilizers) where fatigue resistance, compressive strength, and tribological properties remain crucial issues [9]. Efforts have been directed towards enhancing mechanical and tribological performances of the Al 7075 alloy by incorporation of discontinuous ceramic particles in the manufacture of automotive components such as the engine block, driveshaft, cylinder heads and liners, brake drum, and rotor [10], as well as parts of fuselage like ventral fins, exit guide vanes of engine fan, wings, and fuel access covers $[6,11]$, etc. $\mathrm{Al}_{2} \mathrm{O}_{3}$ particles are preferred as reinforcement due to their greater specific stiffness and oxidation resistivity in comparison to other ceramics, and because their capability of retaining mechanical properties at higher temperatures [12]. Moreover, the thermal stability of $\mathrm{Al}_{2} \mathrm{O}_{3}$ is better than $\mathrm{SiC}$, because of the inert characteristic of $\mathrm{Al}_{2} \mathrm{O}_{3}$ within the Al-melt, thereby eliminating the formation of unwanted and brittle phases [13]. Among the vast processing techniques for developing particulate reinforced AMCs, the stir-casting route is preferred for large scale application in industries, since it is convenient and cost-effective for mass production of any component with a complex geometry of reproducible structures, properties, and reasonably good matrix-reinforcement bonding [14].

Wear, by definition, is loss of material that occurs continuously from the surfaces interacting in relative motion [15]. From the perspective of real-life situations, mechanisms of wear are generally classified as abrasive, adhesive, surface fatigue, and corrosive. Among these, abrasive wear is considered as one of the primary concerns that is frequently encountered in tribological applications constituting about $63 \%$ of the total expenses incurred for wear-related loss [16]. The abrasive mode of wear corresponds to the situation when harder asperities or particles during sliding penetrate a softer surface and displace material in the form of chips or debris, thereby leading to material loss [15]. Depending on the contact environment and the kind of contact, abrasive wear is broadly divided into two- and three-body wear [17]. In the case of two-body abrasion, removal of material is caused by hard asperities rigidly attached to the counter surface by actions of ploughing and cutting [18]. The development of high performance AMCs in certain tribological areas has become one of the prime research interests in the past few decades by understanding of their wear and friction characteristics.

The effects of particle size on the two-body abrasion of $\mathrm{Al} 7075 / 20$ vol.\% $\mathrm{SiC}_{\mathrm{P}}$ composites and the $\mathrm{Al} 7075$ alloy have been investigated by Sheu and Lin [19] using a modified pin-on-disc abrasion device. The authors have reported that the composites exhibit enhanced wear resistance abilities over the unreinforced alloy only when the reinforced particles are larger than the abrasive particles. The larger sized reinforcements, staying intact, can efficiently resist the abrasion against smaller sized abrasives. The wear resistance property and wear mechanism of the composites are similar to those of the unreinforced alloy when reinforcements are smaller in size than abrasives [19]. Lin and Liu [20] have explored the aging effects on two-body abrasive wear behavior of Al-5.0 wt $\% \mathrm{Zn}-2.3 \mathrm{wt} \% \mathrm{Mg}(7000$ series) $/ 7.5 \mathrm{wt} \% \mathrm{SiC}$ composite and its unreinforced alloy. They have indicated that abrasion wear rate is affected by the aging temperature and time, not by aging hardness. The highest abrasion resistance is achieved for over-aged composites due to the stronger interfacial bonding developed between the matrix and reinforcing particles. The effect of abrasive size on the two-body abrasion behavior of the Al LM13-SiC composite has been studied by Das et al. [21]. The wear rate of composite, as well as its unreinforced matrix alloy, abruptly rises when size of the abrasive particle is varied from 60 to $80 \mu \mathrm{m}$. The abrasive wear behavior of stir cast $\mathrm{Al} 2024 / \mathrm{Al}_{2} \mathrm{O}_{3}$ composites, studied by Kök and Özdin [22], infers that the two-body abrasion resistance of composites is considerably higher than that of their base alloy. The wear resistance of composites rises with increasing reinforced particle content (10-30 $\mathrm{wt} \%)$ and size (16 and $32 \mu \mathrm{m})$, and it decreases with increasing load $(2-5 \mathrm{~N})$, abrasive grit size $(20-60 \mu \mathrm{m})$, and sliding distance (150-450 m). Furthermore, the size of particle dominates over the content on the wear resistance property. Wang and Hutchings [23] have reported that beyond the reinforcement content of $20 \mathrm{vol} \%$ in the $\mathrm{Al} 6061$ alloy, two-body abrasive wear resistance decreases against higher sized abrasives due to the excessive fracture and debonding of reinforcements, thus resulting in higher amount of material loss.

The abrasive wear characteristic of AMCs is 
influenced by a hefty number of constraints spanning from material aspects to test conditions [7]. Wear, unlike an inherent material property, may be optimally viewed as a system response that includes intrinsic properties of materials (like mechanical, chemical, metallurgical, and thermal, etc.) in contact and a number of extrinsic factors associated with the tribo-system (such as shape, size and type of abrasive, magnitude of load, roughness, sliding distance, sliding velocity, ambient temperature, nature of lubrication, and setup configuration, etc.) $[15,24]$. The complexity of analyzing abrasive wear behavior of AMCs due to the involvement of diverse parameters (factors) may be resolved by employing statistical tools, such as the design of experiments (DOE) technique [7, 15, 17]. A statistical model developed by Mondal et al. [4] with the help of factorial DOE and linear regression method, successfully predicts two-body abrasion characteristics of $\mathrm{Al} \mathrm{ADC12/10} \mathrm{wt} \%$ $\mathrm{Al}_{2} \mathrm{O}_{3}$ composite under a wide range of abrasive sizes $(30-80 \mu \mathrm{m})$ and loads $(1-7 \mathrm{~N})$. Based on the factorial mode of the DOE method and regression analysis, Sahin and Özdin [15] have developed linear equations to express the abrasive wear rate of $\mathrm{Al} 2011 / \mathrm{SiC}$ composites under a load of $2-8 \mathrm{~N}$ and with an abrasive size of $18-110 \mu \mathrm{m}$. Based on the second-order response surface equation, Kumar and Balasubramanian [7] have generated a mathematical model for predicting the wear rate of $\mathrm{Al} 7075 / \mathrm{SiC}$ composites under two-body abrasion using a pin-on-roller set up.

The Taguchi-based DOE technique is a robust and systematic statistical approach for evaluating individual and interactive effects of test parameters on response outputs, following specifically constructed tables referred to as orthogonal arrays [25]. In the Taguchi parametric design, the experimental layout is represented by these orthogonal arrays, which are highly fractional (as compared to a full factorial design) with least product variance for a given target value [26]. Compared to the dry sliding adhesion of AMCs, where a substantial investigation using DOE tools has already been accomplished, the two-body abrasion particularly of ex-situ AMCs has been addressed only by a few studies to date $[4,7,15,27]$. The reason may be the presence of a large number of external factors associated with the two-body abrasion.

The present study aims to compare tribological characteristics between the Al 7075 alloy reinforced with $20 \mathrm{wt} \% \mathrm{Al}_{2} \mathrm{O}_{3}$ particles and its unreinforced matrix alloy based on the experimental layout of the Taguchi $\mathrm{L}_{27}$ orthogonal array. The comparison (presented as percentage variation) of tribological properties, i.e., wear rates and friction coefficients, between the developed composite and alloy in terms of combinations of different control factors has been emphasized to identify suitable applicable conditions, where the composite exhibits optimized performance in terms of both reduced wear rate and lower coefficient of friction (COF) compared to its matrix alloy under the two-body abrasive mode of wear. Analysis of variance (ANOVA) and second-order response surface equations are utilized to better understand the effects of control factors and develop predictive mathematical models. The multi-response optimization technique with a combined desirability approach is adapted for combined optimization to identify preferable test conditions in which the composite delivers tribological performance superior to its unreinforced alloy. A comprehensive study concerning abrasion mechanisms with respect to variations of load and abrasive size has been performed separately for the alloy and the composite through detailed micrographic views of worn surfaces and produced debris.

\section{Materials and manufacturing process}

The Al-Zn-Mg-Cu (Al 7075) alloy, commercially available as hot extruded rods of $25.5 \mathrm{~mm}$ diameter and $\alpha-\mathrm{Al}_{2} \mathrm{O}_{3}$ particles (Inframat Advanced Materials, USA) of purity $99.5 \%$ were procured for synthesizing composite and alloy specimens. Based on image analysis applied on a substantial number of field emission scanning electron microscope (FE SEM) images and the cumulative frequency statistical tool, the mean diameter of flake-shaped $\mathrm{Al}_{2} \mathrm{O}_{3}$ particles was estimated at $\sim 45 \mu \mathrm{m}$. Liquid metallurgy, i.e., stir casting, was adopted to reinforce $20 \mathrm{wt} \% \mathrm{Al}_{2} \mathrm{O}_{3}$ particles into the matrix of the $\mathrm{Al} 7075$ alloy. The selection of size and content of reinforcement particles was based on the findings of Kök and Özdin [22], who reported that the effect of reinforcement size was more pronounced than the content with respect to the abrasive wear property of AMCs. Further, Wang and Hutchings [23] had shown that above 20 vol.\% of the reinforcement 
amount, the wear resistance of composites decreased, owing to the excessive formation of fragmentation and debonding of reinforcements from $\mathrm{Al}$ matrix.

Achieving uniform distribution of reinforcement is crucial for the development of high performance AMCs. However, attaining the same in the liquid metallurgy method, such as stir casting, is challenging especially for ceramic particles like $\mathrm{Al}_{2} \mathrm{O}_{3}$, which have poor wettability in the Al-melt. Therefore, the judicial selection of various process parameters is of paramount importance. Hence, in this research, these parameters were selected on the basis of several trial tests. In those trial tests, the distribution of particles in the metal matrix was considered as the sole criteria, and the same was assessed by microstructural characterizations and density measurements. For composite preparation, the constant stirring velocity of $500 \mathrm{rpm}$ and stirring duration of $10 \mathrm{~min}$ were chosen [28]. Higher stirring speed caused greater entrapment of gases into the slurry, leading to higher porosity in the casting $[29,30]$. Meanwhile, the lower speed resulted in more settlement of particles, causing a non-uniform particle distribution [31, 32]. The particle distribution was found to improve with extending stirring time up to $10 \mathrm{~min}$, beyond which there was no noticeable change observed from the microstructural investigation. The temperature of the Al-melt (i.e., bath temperature) during particle addition and subsequent stirring was fixed at $800{ }^{\circ} \mathrm{C}$ [28]. At lower bath temperature, particles could not be pulled deep into the melt even by the developed multistage stirrer due to higher viscosity of the melt. Meanwhile, at higher bath temperature, the settlement of particles took place. Both scenarios resulted in inferior particle distribution [33]. Similarly, the pouring temperature was chosen as $800{ }^{\circ} \mathrm{C}$ for composite preparation. The higher pouring temperature developed particle agglomeration in the inter-dendritic areas apart from producing higher porosity [34]. Lower pouring temperature led to the incomplete fill-up of the selected mold, even at pre-heating at $500{ }^{\circ} \mathrm{C}$. This was due to lower fluidity of the slurry specifically in case of composite with high reinforcement content.

The graphite crucible containing small pieces of $\mathrm{Al}$ 7075 alloy weighing about $1 \mathrm{~kg}$, suitable for bottom pouring, was heated inside an electrical resistive furnace. The furnace used the programmable Proportional-Integral-Derivative (PID) controller for measuring and controlling its temperature. A separate arrangement of the thermocouple was made to monitor bath temperature at regular intervals. Once the $\mathrm{Al}$ alloy was melted in the crucible, about $10 \mathrm{~g}$ of magnesium chips was mixed for achieving better wettability between reinforcement particles and molten alloy [35]. The melt was further heated and a constant $800{ }^{\circ} \mathrm{C}$ bath temperature was maintained throughout the particle addition. Mixing of pre-heated particles (at $500{ }^{\circ} \mathrm{C}$ for $1 \mathrm{~h} \mathrm{[36])} \mathrm{in} \mathrm{the} \mathrm{melt} \mathrm{was} \mathrm{performed} \mathrm{at} \mathrm{steady} \mathrm{feed}$ rate by creating a vortex, generated by a three-stage stirrer made of pure graphite. The stirrer rotation was maintained at a constant $500 \mathrm{rpm}$. For effective control of the stirrer speed, a drilling machine equipped with a variable speed setup was arranged to rotate the stirrer. After completion of the particle addition, the stirrer was further rotated at the aforementioned speed for 10 minutes to achieve a homogeneous distribution of reinforcement in the melt [31]. Before pouring the slurry maintained at a temperature of $800{ }^{\circ} \mathrm{C}$, tablets containing $\mathrm{C}_{2} \mathrm{Cl}_{6}$ were immersed in the slurry to degas the melt $[17,37]$. At the time of pouring, the stop-plug at the bottom of the crucible was removed by means of hinge arrangement to allow slurry to fall downwards into the pre-heated cast iron mold. The preparation of the base alloy was performed in the same manner, apart from the incorporation of the particles. The chemical composition of as-cast unreinforced alloy was analyzed with the spectroscopic method, as shown in Table 1, which conforms the prepared alloy to the ASM specification of Al 7075 material. To conduct diverse tests and material characterizations, samples of required dimensions were machined from the as-cast composite and alloy.

\section{Microstructure and hardness}

Specimens of as-cast materials were polished as per standard metallographic practices, using various graded $\mathrm{SiC}$ emery papers starting from coarser to finer,

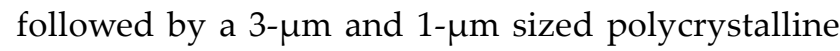
diamond suspension (MetaDi Supreme, Buehler, USA).

Table 1 Chemical composition of as-cast Al 7075 alloy.

\begin{tabular}{cccccccccc}
\hline $\begin{array}{c}\text { Composition } \\
(\text { wt } \%)\end{array}$ & $\mathrm{Cu}$ & $\mathrm{Mg}$ & $\mathrm{Zn}$ & $\mathrm{Cr}$ & $\mathrm{Mn}$ & $\mathrm{Si}$ & $\mathrm{Fe}$ & $\mathrm{Ti}$ & $\mathrm{Al}$ \\
\cline { 2 - 8 } & 1.92 & 2.53 & 6.09 & 0.19 & 0.09 & 0.09 & 0.26 & 0.06 & Balance \\
\hline
\end{tabular}


The optical microscope (Axiovert 40 MAT, Carl Zeiss, Germany) and FE SEM (JSM 7610F, Jeol, Japan) with an attached energy dispersive X-ray (EDX) facility (X-max 50, Oxford, UK) were utilized to perform microstructural examinations of prepared materials without etching.

Optical microscope images of the base alloy and composite are presented in Fig. 1. Intermetallic compounds present in the optical microstructure of the alloy (Fig. 1(a)) are shown further in the magnified FE SEM image in Fig. 1(c). An optical micrograph of composite (Fig. 1(b)) reveals the presence of flake shaped embedded particulates (black coloured), which are identified as $\mathrm{Al}_{2} \mathrm{O}_{3}$ particles by employing elemental
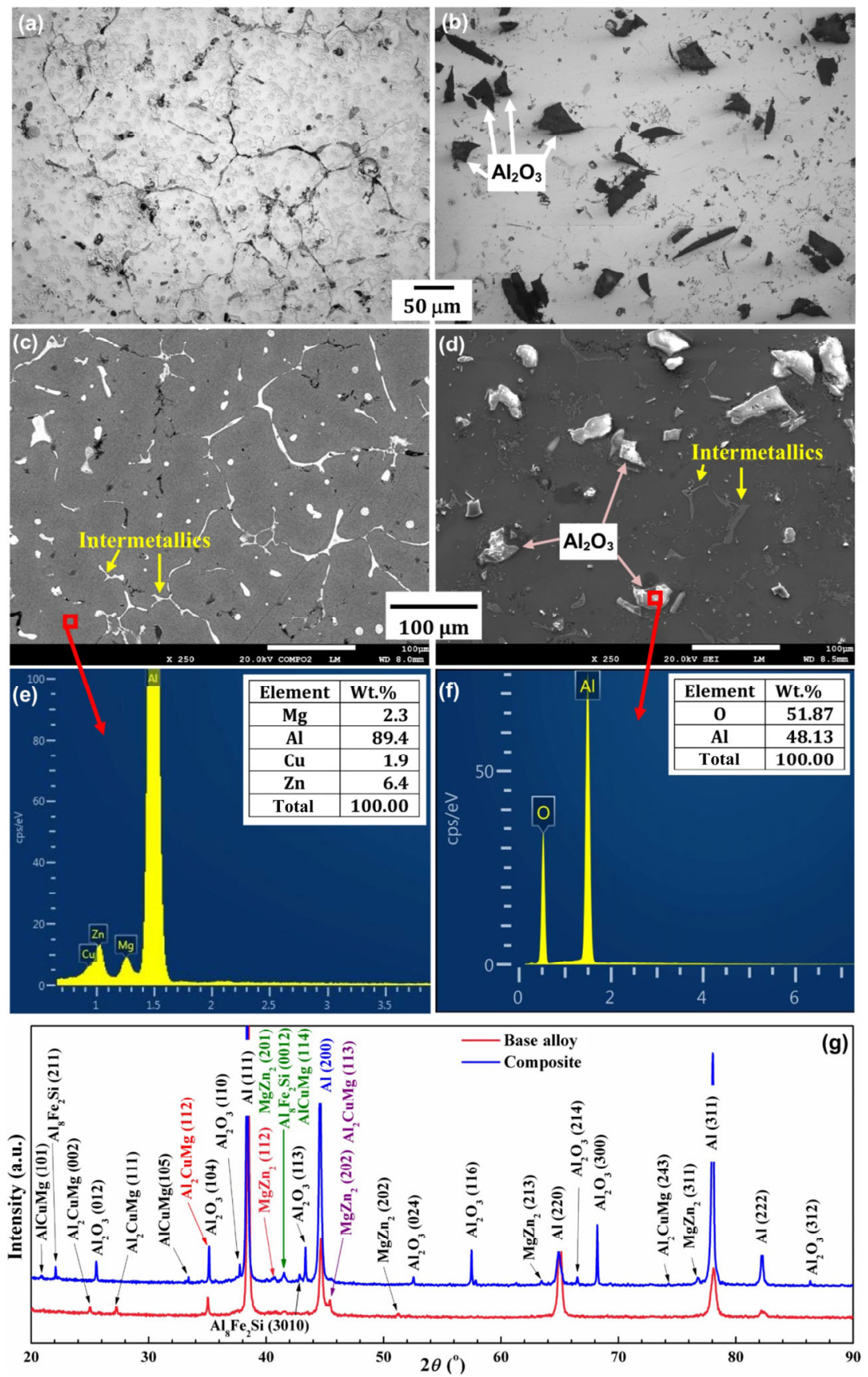

Fig. 1 Typical optical (a-b) and FE SEM micrographs (c-d) of as-cast alloy (a, c) and composite (b, d), (e) and (f) show EDX profiles along with results of semi-quantitative elemental analyses corresponding to the marked areas in (c) and (d), respectively, and (g) presents XRD line profiles of base alloy and composite. 
EDX analysis (Figs. 1(d) and 1(f)). Both optical and FE SEM images confirm nearly homogenous distribution of particles incorporated through stir casting route into the matrix of $\mathrm{Al}-\mathrm{Zn}-\mathrm{Mg}-\mathrm{Cu}$ alloy apart from presence of intermetallics (Figs. 1(c) and 1(d)). The FE SEM image in Fig. 1(c) depicts the distribution of thin elongated intermetallics in the inter-dendritic areas of the alloy. Elemental analysis performed on the dendritic area of the base alloy conforms to the chemical composition of the standard Al 7075 alloy (Fig. 1(e)). Intermetallics in the as-cast alloy and composite materials are identified primarily by the XRD technique as $\mathrm{MgZn}_{2}$ and $\mathrm{Al}_{2} \mathrm{CuMg}$, with a slight quantity of $\mathrm{Al}_{8} \mathrm{Fe}_{2} \mathrm{Si}$ (Fig. 1(g)) [38]. The natural formation of $\mathrm{Al}_{2} \mathrm{CuMg}$ and $\mathrm{MgZn}_{2}$ intermetallic compounds during liquid processing of an $\mathrm{Al}-\mathrm{Zn}-\mathrm{Mg}-\mathrm{Cu}$ alloy has been reported in previous studies $[39,40] . \mathrm{Al}_{8} \mathrm{Fe}_{2} \mathrm{Si}$ is regarded as an inclusion and precipitated during casting of the Al 7075 alloy [39]. Evidence of a considerable amount of $\mathrm{Al}_{2} \mathrm{O}_{3}$ particles in the cast composite material is also confirmed by XRD line profile analyses (Fig. 1(g)) [38].

Based on Archimedes principle, measurement of density was carried out using a highly precise microbalance (CPA225D, Sartorius $\mathrm{GmbH}$ ) with a density determination kit and deionized water as liquid medium. The mean density value was calculated after measuring densities of at least five different specimens prepared for studying microstructure, wear, and hardness. The mixture rule was employed to compute the theoretical density of as-cast composite material considering standard density values of the base alloy as 2.81 and the $\mathrm{Al}_{2} \mathrm{O}_{3}$ particle as $3.97 \mathrm{~g} \cdot \mathrm{cm}^{-3}$ [41]. The porosity of the respective material was obtained by comparing densities between the measured and theoretical values [42]. With the addition of $20 \mathrm{wt} \%$ $\mathrm{Al}_{2} \mathrm{O}_{3}$ particles, the composite exhibits higher density $\left(2.73 \pm 0.02 \mathrm{~g} \cdot \mathrm{cm}^{-3}\right)$ than unreinforced alloy $(2.66 \pm$ $\left.0.01 \mathrm{~g} \cdot \mathrm{cm}^{-3}\right)$, since theoretical densities of $\mathrm{Al} 7075$ alloy and $\mathrm{Al}_{2} \mathrm{O}_{3}$ are $2.81 \mathrm{~g} \cdot \mathrm{cm}^{-3}$ [43] and $3.9 \mathrm{~g} \cdot \mathrm{cm}^{-3}$ [44], respectively. The porosity of the composite is measured as $8.5 \%$ in comparison to that of $5.2 \%$ for the base alloy. Higher porosity content in the composite is attributed to the incorporation of particles which increase gas entrapments [35, 41].

The macro-hardness tester (Innovatest universal hardness tester, Verzus 750 CCD, Netherlands) applying an indentation load of $5 \mathrm{kgf}$ on metallographically polished specimens for a dwell time of $30 \mathrm{~s}$ was used to measure bulk hardness of as-cast materials. For a specific material, the reported mean value of hardness in Vickers hardness number (VHN) was estimated based on hardness values taken randomly at seven different spots. An improvement of $26.5 \%$ in bulk hardness of composite material $(137.3 \pm 4.4 \mathrm{VHN})$ is noticed over the base alloy $(108.5 \pm 3.7 \mathrm{VHN})$. The enhanced bulk hardness of the composite provides better tribological properties in comparison to its matrix alloy $[22,41]$.

\section{Design of experiments}

\subsection{Tribological characterizations}

Generally, two-body abrasion is considered as highstress wear, since abrasive particles are fractured. However, these remain intact in three-body abrasion that is therefore known as low-stress abrasive wear [24, 45]. Tests of two-body abrasion in dry conditions were performed utilizing a pin-on-disc tribometer (UMT 2, CETR, USA) at room temperature $\left(20 \pm 3{ }^{\circ} \mathrm{C}\right.$, relative humidity of $65 \% \pm 5 \%$ ) following the specifications of ASTM: G99-05(2010) [37]. Test specimens were made by machining as-cast materials in the form of cylindrical pins (6.3-mm diameter $\times 40-\mathrm{mm}$ length). Waterproof emery papers (Jawan Brand, Carborundum Universal Limited, India) of different grit-sized SiC abrasives were considered as abrasive medium by sticking these papers on a horizontally rotating SS304 disc of $70-\mathrm{mm}$ diameter and $6.6-\mathrm{mm}$ thickness. The wear test specimen (pin) was vertically pressed against the horizontal counter surface by means of pre-selected magnitudes of load governed by the built-in close-loop servo control setup of the tribometer. Pins were held fixed at a track diameter of $56 \mathrm{~mm}$ on the counter surface of rotating disc. The wear test was run up to a sliding distance of $10 \mathrm{~m}$ on a single abrasive paper. The selection of sliding distance on a particular paper was based on observations of several trial test results indicating severe degradation in the cutting ability of $\mathrm{SiC}$ abrasives beyond a sliding distance of $10 \mathrm{~m}$, as abrasives were fractured and consequently pulled 
out of the paper $[4,19]$. The fixed sliding distance of $10 \mathrm{~m}$ was confirmed by observing variations in COF line profiles vs. sliding distance provided by the tribometer as well as FE SEM examinations of abraded papers. Prior to each test, the contact surface of the cylindrical pin was polished with 1200-grit abrasive paper using the same tribometer under a low load of $10 \mathrm{~N}$ to achieve a flat surface to maintain full contact against the counter surface. Wear tests were carried out against $\mathrm{SiC}$ abrasive paper of 400,600, and 1,000 grit size. The mean spherical diameter of $\mathrm{SiC}$ abrasives of 400,600 , and 1,000 grit papers are estimated to be $\sim 30$, 23 , and $13 \mu \mathrm{m}$, respectively. The size of the $\mathrm{SiC}$ abrasive was calculated using Image J software considering ten FE SEM images for each grit size paper.

The estimation of wear rate was based on the weight loss technique $[3,41]$. Pins were cleaned with the help of an ultrasonic cleaner (LMUC-2A, Labman, India) before and after each test. Pin weight was measured on a $10^{-5} \mathrm{~g}$ precision microbalance (CPA225D, Sartorius, Germany). The weight loss of the pin was calculated from the difference in weights measured before and after each abrasion test. This weight loss divided by the experimentally obtained density value was converted to a volume loss. The wear rate ' $\mathrm{W}_{\mathrm{r}}{ }^{\prime}\left(\mathrm{mm}^{3} \cdot \mathrm{m}^{-1}\right)$ is computed as:

$$
\mathrm{W}_{\mathrm{r}}=\Delta m / \rho \cdot L
$$

where $\Delta m$ represents material loss (g), $\rho$ is the density $\left(\mathrm{g} \cdot \mathrm{cm}^{-3}\right)$, and $L$ denotes sliding distance $(\mathrm{m})$. The frictional force during the wear test was measured by the DFH-100 load-sensor attached to the tribometer and recorded throughout the measurement. Respective COF values were obtained dividing the recorded frictional force by the applied load. The line profile of COF against sliding distance was generated after multiplying the test duration by the chosen sliding velocity. The mean value of COF was computed considering the steady-state region only in the COF graph plotted against the sliding distance. A minimum of two tests were carried out under the similar operative condition to ensure repeatability of the obtained result. Detailed studies on micro-mechanisms pertaining to two-body abrasion were conducted by examining selective worn surfaces of test pins and wear debris using FE SEM along with EDX technology.

\subsection{Taguchi design of experiments}

Test parameters affecting two-body abrasion are mainly the type and size of abrasives, magnitude of normal load, setup configuration, state of lubrication, and positioning of the specimen with respect to the counter body, etc. [15, 24]. Among various parameters, load, abrasive size, sliding distance, and sliding velocity were emphasized as control factors in the present study, since these were primarily assumed to be predominant in the two-body abrasion of metallic components [3, $4,15,17,21,22,27,37]$. The kind of influence of a particular factor on an output (response) is better realized when at least three levels for that factor are considered. Therefore, the experimental layout here considered three distinct levels for each of the four factors. However, this experimental plan requires a total of $81\left(3^{4}\right)$ test runs, if a full factorial design plan was followed. In contrast to a typical full factorial plan, the experiment design following the Taguchi $\mathrm{L}_{27}$ orthogonal array consists of only 27 test runs, by which relationships between the control factors and the output variables are well established with minimal noise, thereby saving significant experimental expense [46-48]. The number of tests as well as the experimental layout in details are provided by the Taguchi orthogonal array. The selection of an orthogonal array is based on considering that the total degrees of freedom of the array need to be higher than or equal to the sum of degrees of freedom of individual and interacting factors. The array is likewise designed in such a way that each and every level of a factor is given equal importance and hence balanced [25]. The present study considered four factors (i.e., load, abrasive size, sliding distance, and sliding velocity, denoted as A, B, C, and D, respectively) each consisting of three different levels. The magnitudes of selected factors corresponding to the levels as well as the detailed experimental plan based on Taguchi $\mathrm{L}_{27}$ design are shown in Table 2.

In Taguchi based DOE, the repetition of tests implies the obvious presence of a variance index defined as signal-to-noise $(\mathrm{S} / \mathrm{N})$ ratio. Regardless of the kind of quality characteristics, a higher value of the $\mathrm{S} / \mathrm{N}$ ratio is always desirable, since it signifies less product variance around a set target [49]. The $\mathrm{S} / \mathrm{N}$ ratio is measured in units of decibel $(\mathrm{dB})$ and mathematically 
Table 2 Experimental layout following Taguchi $\mathrm{L}_{27}$ orthogonal array.

\begin{tabular}{|c|c|c|c|c|}
\hline Exp. No. & $\begin{array}{l}\text { Load } \\
(\mathrm{N})\end{array}$ & $\begin{array}{l}\text { Abrasive size } \\
\qquad(\mu \mathrm{m})\end{array}$ & $\begin{array}{l}\text { Distance } \\
\quad(\mathrm{m})\end{array}$ & $\begin{array}{l}\text { Velocity } \\
\left(\mathrm{m} \cdot \mathrm{s}^{-1}\right)\end{array}$ \\
\hline 1 & 20 & 13 & 10 & 0.25 \\
\hline 2 & 20 & 13 & 20 & 0.50 \\
\hline 3 & 20 & 13 & 40 & 1.00 \\
\hline 4 & 20 & 23 & 10 & 0.25 \\
\hline 5 & 20 & 23 & 20 & 0.50 \\
\hline 6 & 20 & 23 & 40 & 1.00 \\
\hline 7 & 20 & 30 & 10 & 0.25 \\
\hline 8 & 20 & 30 & 20 & 0.50 \\
\hline 9 & 20 & 30 & 40 & 1.00 \\
\hline 10 & 40 & 13 & 10 & 0.50 \\
\hline 11 & 40 & 13 & 20 & 1.00 \\
\hline 12 & 40 & 13 & 40 & 0.25 \\
\hline 13 & 40 & 23 & 10 & 0.50 \\
\hline 14 & 40 & 23 & 20 & 1.00 \\
\hline 15 & 40 & 23 & 40 & 0.25 \\
\hline 16 & 40 & 30 & 10 & 0.50 \\
\hline 17 & 40 & 30 & 20 & 1.00 \\
\hline 18 & 40 & 30 & 40 & 0.25 \\
\hline 19 & 80 & 13 & 10 & 1.00 \\
\hline 20 & 80 & 13 & 20 & 0.25 \\
\hline 21 & 80 & 13 & 40 & 0.50 \\
\hline 22 & 80 & 23 & 10 & 1.00 \\
\hline 23 & 80 & 23 & 20 & 0.25 \\
\hline 24 & 80 & 23 & 40 & 0.50 \\
\hline 25 & 80 & 30 & 10 & 1.00 \\
\hline 26 & 80 & 30 & 20 & 0.25 \\
\hline 27 & 80 & 30 & 40 & 0.50 \\
\hline
\end{tabular}

presented as:

$$
\mathrm{S} / \mathrm{N}=-10 \log _{10}(\mathrm{MSD})
$$

where MSD represents the mean square deviation from the target value of a particular performance. Since the $\mathrm{S} / \mathrm{N}$ ratio is expected to be always greater in magnitude, irrespective of the nature of quality characteristics, the MSD value, therefore, should be a smaller one in view of minimizing noise (errors) as much as possible [25]. The use of MSD is very specific, subject to the types of quality characteristics categorized as smaller, nominal, and larger. In this study, larger-is-better quality characteristic is selected, since the study compares tribological properties of the wear rate and COF between the composite and its matrix alloy. The emphasis has been imparted to identify the maximum variations among their tribological properties to optimize settings of the four control factors. Based on the Taguchi $\mathrm{L}_{27}$ design layout, wear rates and $\mathrm{COF}$ values of the unreinforced alloy and composite were measured separately and compared among to each other. The variation (\%) in the wear rate between the composite and base alloy, denoted by $\Delta W R$, is expressed in the present study as [50]:

$$
\Delta \mathrm{WR}=\left(\frac{\mathrm{WR}_{\mathrm{A}}-\mathrm{WR}}{\mathrm{WR}}\right) \times 100
$$

where $W R_{A}$ is the wear rate of the base alloy; $W R_{C}$ is the wear rate of the composite.

The variation (\%) in co-efficient (COF) values between the composite and alloy, denoted by $\triangle \mathrm{COF}$, is presented in mathematical form as:

$$
\Delta \mathrm{COF}=\left(\frac{\mathrm{COF}_{\mathrm{A}}-\mathrm{COF}_{\mathrm{C}}}{\mathrm{COF}_{\mathrm{A}}}\right) \times 100
$$

where $\mathrm{COF}_{\mathrm{A}}$ is the $\mathrm{COF}$ of the base alloy; $\mathrm{COF}_{\mathrm{C}}$ is the $\mathrm{COF}$ of the composite.

For the larger-is-better quality characteristic [25], the mathematical expression of MSD is as follows:

$$
\operatorname{MSD}=\left(\frac{1}{y_{1}^{2}}+\frac{1}{y_{2}^{2}}+\ldots+\frac{1}{y_{n}^{2}}\right) / n
$$

where $y_{1}, y_{2}, y_{3}, \ldots, y_{n}$ indicate data points, i.e., experimental results, and $n$ is the number of repetitions. The statistical analyses have been performed using MINITAB 16 software. Considering S/N ratios of the response (output) characteristic, ANOVA has been employed to determine significant parameters (factors) affecting the quality characteristics of $\triangle \mathrm{WR}$ and $\Delta \mathrm{COF}$. In Taguchi based DOE, a factor with $n$ number of levels consists of $(n-1)$ number of degrees of freedom (DFs). ANOVA is evaluated on the basis of following fundamental steps [51]:

total sum of squares,

$$
\mathrm{SS}_{\mathrm{T}}=\sum_{i=1}^{N}(\mathrm{~S} / \mathrm{N})_{i}^{2}-\left(\frac{T^{2}}{N}\right)
$$


sum of squares for a factor $X$,

$$
\mathrm{SS}_{X}=\sum_{i=1}^{L_{X}} \frac{(\mathrm{S} / \mathrm{N})_{X_{i}}^{2}}{n_{X_{i}}}-\left(\frac{T^{2}}{N}\right)
$$

total DFs,

$$
\mathrm{DF}_{\text {Total }}=N-1
$$

variance of the factor $X$,

$$
\mathrm{V}_{\text {FactorX }}=\frac{\mathrm{SS}_{X}}{\mathrm{DF}_{\text {FactorX }}}
$$

variance ratio for the factor $X$,

$$
F_{X}=\frac{\mathrm{V}_{\text {FactorX }}}{\mathrm{V}_{\text {Error }}}
$$

$\%$ contribution of the factor $X=\left(\frac{\mathrm{SS}_{X}}{\mathrm{SS}_{T}}\right) \times 100 \%$

where $T$ presents the sum of total $\mathrm{S} / \mathrm{N}$ ratios; $N$ stands for the total number of tests; $L_{X}$ indicates the number of levels of the factor $X ;(\mathrm{S} / \mathrm{N})_{X_{i}}$ signifies total values of $\mathrm{S} / \mathrm{N}$ ratios pertaining to the factor $X$ at its $i$-th level; $n_{X_{i}}$ is the number of the $i$-th level of the factor $X$ present; $\mathrm{V}_{\text {Error }}$ represents variance of the error. Based on a 5\% (0.05) significance level, the statistical analysis has been performed considering the confidence level of $95 \%$, which means that $95 \%$ of the intervals would match the true value of the population [52-54]. Control factors and their interactions are considered statistically significant, provided that their probability values (p-values) are lower than 0.05 [25, 55]. From Eq. (11), the column at the last in the ANOVA table presents percentage contributions of the associated design parameters to the response characteristic. The contribution of any design parameter (factor/interaction of factors) is regarded physically significant on an output when its contribution is larger than that of error [51]. Regression equations based on full quadratic response surface method have been generated to develop predictive models. Adequacy of the developed models has been ensured by co-relational coefficients, such as $R-S q$ which is defined as coefficient of determination. Consistency of the models is also verified by comparing predictive results with experiment.

\section{Results and discussion}

\subsection{Tribological behaviour}

Based on the Taguchi $\mathrm{L}_{27}$ orthogonal experimental plan, the wear rates and COF values of alloy and composite are summarized in Table 3. The graphical representation in Fig. 2 provides ease of understanding the variations in wear rates and COF values between the alloy and composite against individual test runs (Table 3). Figure 2 shows that the wear rate and the COF of the base alloy are always greater than that of the composite under identical operating conditions. The difference in wear rates between the alloy and composite is found to become maximum at the greatest magnitude of load, i.e., $80 \mathrm{~N}$ and against the highest abrasive size of $30 \mu \mathrm{m}$ (Experiment No. 25, Fig. 2). The maximum difference in COF $\mathrm{v}$ alues between the alloy and composite is noticed also at the greatest magnitude of load, however against a different, median abrasive size of $23 \mu \mathrm{m}$ (Experiment No. 24).

The test results exhibiting percentage variations in abrasive wear rates and COF values between alloy and composite are presented in Table 3. The results listed in Table 3 infer that the percent variation in wear rates amongst alloy and composite (i.e., $\Delta \mathrm{WR}$ ) turns to be higher with increasing load and decreasing abrasive size. Similarly, the variation in $\mathrm{COF}$ values between these two materials (i.e., $\triangle \mathrm{COF}$ ) becomes greater with reduction in abrasive size but under an intermediate range of applied load. The positive results of both $\triangle \mathrm{WR}$ and $\triangle \mathrm{COF}$ considering Eqs. (3) and (4), respectively reaffirm that the unreinforced alloy has higher wear rates and COF values than the composite under a set of similar test parameters. The enhanced wear resistance of the composite in comparison to the base alloy is attributed primarily to the presence of hard embedded ceramic reinforcing particles that deter the penetration of $\mathrm{SiC}$ abrasives during sliding $[7,22,37]$. Ceramic reinforcements protruded from the alloy matrix act as load bearing components enhancing the wear resistance ability of the composite [7]. As in a previous report earlier, the two-body abrasive wear resistance of AMCs improves with increasing reinforcement content and size of reinforcing particulates; whereas the latter dominates over its content with respect to the wear resistance property [22]. 
Table 3 Experimental results using Taguchi $\mathrm{L}_{27}$ orthogonal array.

\begin{tabular}{|c|c|c|c|c|c|c|c|c|}
\hline \multirow{2}{*}{$\begin{array}{l}\text { Exp. } \\
\text { No. }\end{array}$} & \multicolumn{2}{|c|}{$\mathrm{WR}\left(\mathrm{mm}^{3} \cdot \mathrm{m}^{-1}\right)$} & \multicolumn{2}{|c|}{$\mathrm{COF}$} & \multicolumn{2}{|c|}{$\Delta \mathrm{WR}(\%)$} & \multicolumn{2}{|c|}{$\Delta \mathrm{COF}(\%)$} \\
\hline & $\mathrm{WR}_{\mathrm{A}}$ & $\mathrm{WR}_{\mathrm{C}}$ & $\mathrm{COF}_{\mathrm{A}}$ & $\mathrm{COF}_{\mathrm{C}}$ & Mean & $\mathrm{S} / \mathrm{N}$ ratio & Mean & $\mathrm{S} / \mathrm{N}$ ratio \\
\hline 1 & $0.3902 \pm 0.008$ & $0.1029 \pm 0.002$ & $0.6546 \pm 0.006$ & $0.4495 \pm 0.004$ & 73.6289 & 37.3410 & 31.3321 & 29.9198 \\
\hline 2 & $0.3952 \pm 0.006$ & $0.0928 \pm 0.009$ & $0.6699 \pm 0.006$ & $0.4247 \pm 0.008$ & 76.5182 & 37.6753 & 36.6025 & 31.2702 \\
\hline 3 & $0.3785 \pm 0.005$ & $0.1363 \pm 0.006$ & $0.6041 \pm 0.008$ & $0.4519 \pm 0.005$ & 63.9894 & 36.1222 & 25.1945 & 28.0261 \\
\hline 4 & $0.5862 \pm 0.009$ & $0.2470 \pm 0.007$ & $0.7007 \pm 0.009$ & $0.5543 \pm 0.010$ & 57.8642 & 35.2482 & 20.8934 & 26.4002 \\
\hline 5 & $0.6545 \pm 0.008$ & $0.2309 \pm 0.011$ & $0.6970 \pm 0.014$ & $0.5199 \pm 0.007$ & 64.7212 & 36.2209 & 25.4089 & 28.0997 \\
\hline 6 & $0.6500 \pm 0.004$ & $0.2029 \pm 0.005$ & $0.7119 \pm 0.008$ & $0.5290 \pm 0.005$ & 68.7846 & 36.7498 & 25.6918 & 28.1959 \\
\hline 7 & $0.6467 \pm 0.009$ & $0.4513 \pm 0.008$ & $0.7195 \pm 0.007$ & $0.6245 \pm 0.008$ & 30.2149 & 29.6044 & 13.2036 & 22.4139 \\
\hline 8 & $0.6576 \pm 0.009$ & $0.3958 \pm 0.009$ & $0.6731 \pm 0.006$ & $0.6088 \pm 0.008$ & 39.8114 & 32.0002 & 9.5528 & 19.6026 \\
\hline 9 & $0.7469 \pm 0.008$ & $0.3907 \pm 0.005$ & $0.7078 \pm 0.009$ & $0.6147 \pm 0.006$ & 47.6905 & 33.5686 & 13.1534 & 22.3808 \\
\hline 10 & $0.6523 \pm 0.004$ & $0.1624 \pm 0.007$ & $0.6284 \pm 0.007$ & $0.4235 \pm 0.008$ & 75.1035 & 37.5132 & 32.6066 & 30.2661 \\
\hline 11 & $0.5990 \pm 0.008$ & $0.1113 \pm 0.006$ & $0.6208 \pm 0.005$ & $0.3964 \pm 0.009$ & 81.4190 & 38.2145 & 36.1469 & 31.1614 \\
\hline 12 & $0.5127 \pm 0.026$ & $0.1065 \pm 0.005$ & $0.6339 \pm 0.006$ & $0.4198 \pm 0.007$ & 79.2276 & 37.9775 & 33.7750 & 30.5719 \\
\hline 13 & $1.0361 \pm 0.009$ & $0.2713 \pm 0.005$ & $0.6927 \pm 0.002$ & $0.5178 \pm 0.005$ & 73.8153 & 37.3629 & 25.2490 & 28.0449 \\
\hline 14 & $1.0736 \pm 0.009$ & $0.2352 \pm 0.005$ & $0.6873 \pm 0.011$ & $0.4872 \pm 0.009$ & 78.0924 & 37.8522 & 29.1139 & 29.2820 \\
\hline 15 & $0.9513 \pm 0.008$ & $0.2710 \pm 0.006$ & $0.6875 \pm 0.009$ & $0.5247 \pm 0.008$ & 71.5127 & 37.0877 & 23.6800 & 27.4876 \\
\hline 16 & $1.0639 \pm 0.007$ & $0.5643 \pm 0.008$ & $0.7037 \pm 0.008$ & $0.6028 \pm 0.005$ & 46.9593 & 33.4344 & 14.3385 & 23.1301 \\
\hline 17 & $1.5870 \pm 0.007$ & $0.5015 \pm 0.014$ & $0.7269 \pm 0.009$ & $0.5679 \pm 0.007$ & 68.3995 & 36.7011 & 21.8737 & 26.7984 \\
\hline 18 & $1.0830 \pm 0.009$ & $0.5579 \pm 0.009$ & $0.7001 \pm 0.004$ & $0.6003 \pm 0.006$ & 48.4857 & 33.7123 & 14.2551 & 23.0794 \\
\hline 19 & $0.6253 \pm 0.009$ & $0.1845 \pm 0.009$ & $0.5207 \pm 0.008$ & $0.4146 \pm 0.013$ & 70.4942 & 36.9631 & 20.3764 & 26.1826 \\
\hline 20 & $0.5188 \pm 0.010$ & $0.1469 \pm 0.005$ & $0.5314 \pm 0.007$ & $0.4321 \pm 0.009$ & 71.6847 & 37.1085 & 18.6865 & 25.4306 \\
\hline 21 & $0.5120 \pm 0.005$ & $0.1271 \pm 0.003$ & $0.5860 \pm 0.009$ & $0.4292 \pm 0.008$ & 75.1758 & 37.5216 & 26.7577 & 28.5490 \\
\hline 22 & $1.6140 \pm 0.004$ & $0.2930 \pm 0.004$ & $0.6408 \pm 0.008$ & $0.4572 \pm 0.006$ & 81.8463 & 38.2600 & 28.6517 & 29.1430 \\
\hline 23 & $1.3498 \pm 0.005$ & $0.2958 \pm 0.006$ & $0.6823 \pm 0.007$ & $0.4722 \pm 0.003$ & 78.0856 & 37.8514 & 30.7929 & 29.7690 \\
\hline 24 & $1.3329 \pm 0.008$ & $0.2928 \pm 0.009$ & $0.6908 \pm 0.008$ & $0.4422 \pm 0.008$ & 78.0329 & 37.8456 & 35.9873 & 31.1230 \\
\hline 25 & $2.2900 \pm 0.002$ & $0.4315 \pm 0.006$ & $0.6948 \pm 0.010$ & $0.5235 \pm 0.006$ & 81.1572 & 38.1865 & 24.6546 & 27.8380 \\
\hline 26 & $2.0151 \pm 0.008$ & $0.7848 \pm 0.005$ & $0.6988 \pm 0.007$ & $0.5621 \pm 0.009$ & 61.0540 & 35.7143 & 19.5621 & 25.8283 \\
\hline 27 & $2.1675 \pm 0.007$ & $0.5433 \pm 0.007$ & $0.7058 \pm 0.008$ & $0.5430 \pm 0.009$ & 74.9343 & 37.4936 & 23.0660 & 27.2595 \\
\hline
\end{tabular}

WR: wear rate in $\mathrm{mm}^{3} \cdot \mathrm{m}^{-1}, \mathrm{WR}_{\mathrm{A}}$ : wear rate of alloy, $\mathrm{WR}_{\mathrm{C}}$ : wear rate of composite COF: coefficient of friction, $\mathrm{COF}_{\mathrm{A}}$ : $\mathrm{COF}$ of alloy, $\mathrm{COF}_{\mathrm{C}}$ : $\mathrm{COF}$ of composite
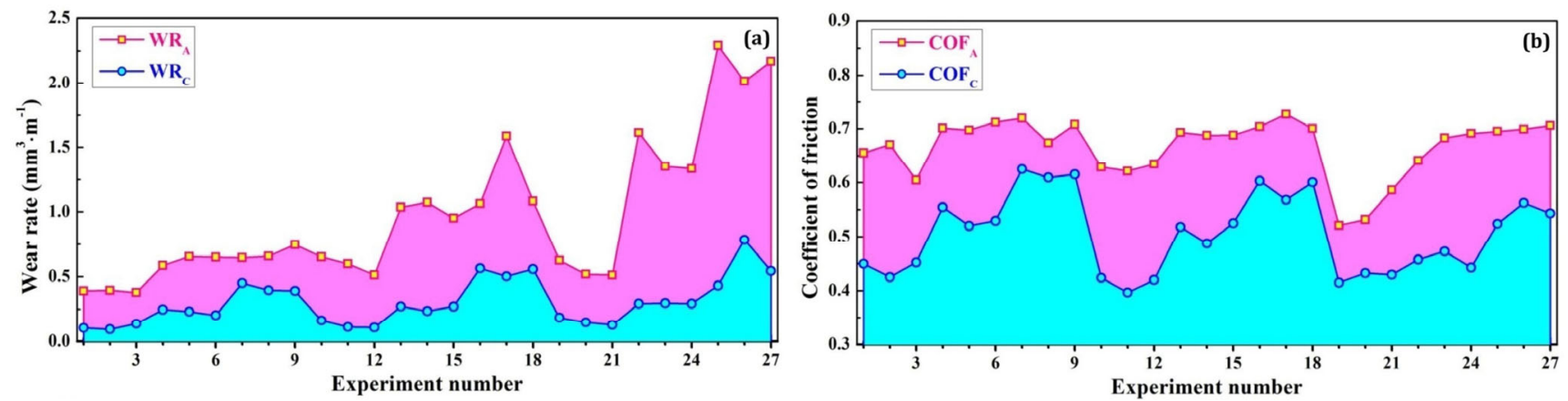

Fig. 2 Graphical presentation comparing wear rates (a) and coefficients of friction (b) between alloy and composite in individual experiments.

Lower values of the COF are generally desirable in tribological applications to minimize frictional losses [56]. The value of COF depends on number of asperity junctions formed and the strength of these junctions that altogether determine the magnitude of the force required to shear off junctions during sliding [57]. In 
general, the real area of contact is reduced for the composite because of discontinuosly embedded ceramic partcles protruding from matrix [37]. Therefore, asperity junctions formed are lesser in number for the composite. During the two-body abrasion, in case of the composite, asperity junctions are formed mostly between $\mathrm{SiC}$ abrasives and $\mathrm{Al}_{2} \mathrm{O}_{3}$ reinforcements, leading to a reduced strength of asperity junctions due to a depleted plastic deformation at the asperity contact of two ceramic particles [37, 58]. Consequently, the amount of energy needed for shearing off junctions at asperity contacts is considerably lower for composites, resulting in lower COF.

\subsection{Mechanisms of wear}

The extent of abrasive wear of AMCs as well as their matrix materials is governed mostly by the load and abrasive size [4, 15, 27, 37]. For better realization of the two-body abrasion mechanisms, abraded surfaces and generated debris corresponding to the tests performed under minimum $(20 \mathrm{~N})$ and maximum $(80 \mathrm{~N})$ load, and against the lowest $(13 \mu \mathrm{m})$ and the highest $(30 \mu \mathrm{m})$-sized abrasives were chosen for FE SEM examinations separately for the alloy and composite specimens. The effect of $\mathrm{SiC}$ abrasive size on two-body abrasion is depicted in Fig. 3 for the base alloy and in Fig. 4 for the composite, while keeping load, sliding distance, and velocity fixed at $40 \mathrm{~N}, 20 \mathrm{~m}$, and $0.5 \mathrm{~m} \cdot \mathrm{s}^{-1}$, respectively. Similarly, the influence of load is presented in Fig. 5 for the unreinforced alloy and Fig. 6 for the composite under a constant operating condition of $23 \mu \mathrm{m}$ sized abrasives, $20 \mathrm{~m}$ sliding distance, and $0.5 \mathrm{~m} \cdot \mathrm{s}^{-1}$ velocity.

The abrasion mechanism is largely dominated by the size of the abrasive $[19,24,59]$. The extent of its dominance is determined by a ratio $w / r$, where $w$ and $r$ represent the groove width on the abraded surface and the tip radius of the abrasive particle, respectively. Plastic deformation is reported to dominate in the range of $0.28<w / r<0.87$; whereas the microcutting mechanism (i.e., formation of chips) initiates when the value of $w / r$ is above 0.87 [24]. Irrespective of twoor three-body abrasion, there is a critical size of abrasives [60]. Up to the critical dimension, material removal increases in terms of volume, with an increase in abrasive size. At the critical dimension, material loss due to abrasives is at its largest, in terms of the size of debris generated [61]. Beyond this critical size, the wear rate is almost independent of abrasive size. The difference in hardness values between the abrasive and the worn material aides in determining this critical dimension [62]. Further, Wang and Rack [63] have introduced the term relative penetration depth, which is expressed as the ratio of the mean penetration depth of the abrasive particle $h$ to the mean diameter of the reinforcing particle $d$. For $h>d$, the wear rate is assumed to increase; whereas the trend is opposite when $h<d$ [63].

The images in Fig. 3 show that higher sized abrasives cause more damage to the surface of the alloy, since the grooves developed are distinctly prominent and deep on the abraded surface. The worn surface of unreinforced alloy abraded against lower sized abrasives rather exhibits intermetallic compounds (phases) in the inter-dendritic regions, owing to their lower penetrating ability (Figs. 3(a) and 3(c)). The severity of worn surface (Figs. 3(b) and 3(d)) is characterized by excessive scratches and grooves, which are both representative of plastic deformation [64]. With a reduction in the abrasive size, the number of abrasives increases for a specific area of an abrasive paper, leading to less stress generated on a single abrasive particle, since the normal load of same magnitude is shared among the higher number of abrasives. This results in a lower penetration ability of abrasives into the soft matrix [24, 65]. Therefore, with an increasing abrasive size from 13 to $30 \mu \mathrm{m}$, the nature of alloy debris alters from short and fragile microchips to long and curly shaped microchips (Figs. 3(e) and 3(f)). As compared to the wear debris collected after abrading against the 30- $\mu \mathrm{m}$ sized $\mathrm{SiC}$ abrasive, the debris formed against the $13-\mu \mathrm{m}$ sized abrasive consists of a very few number of microchips (Fig. 3(e)). The formation of microchips is the result of a microcutting mechanism [64] that prevails when a soft ductile surface is abraded against large abrasives.

Like unreinforced alloy, the scratches and grooves along the sliding direction are pronounced on the worn surface of the composite after abrading against largest abrasives (Figs. 4(a) and 4(b)). In fact, the surface of the composite presents visible $\mathrm{Al}_{2} \mathrm{O}_{3}$ reinforcements protruded from the $\mathrm{Al}$ matrix (Fig. 4(a)) when 

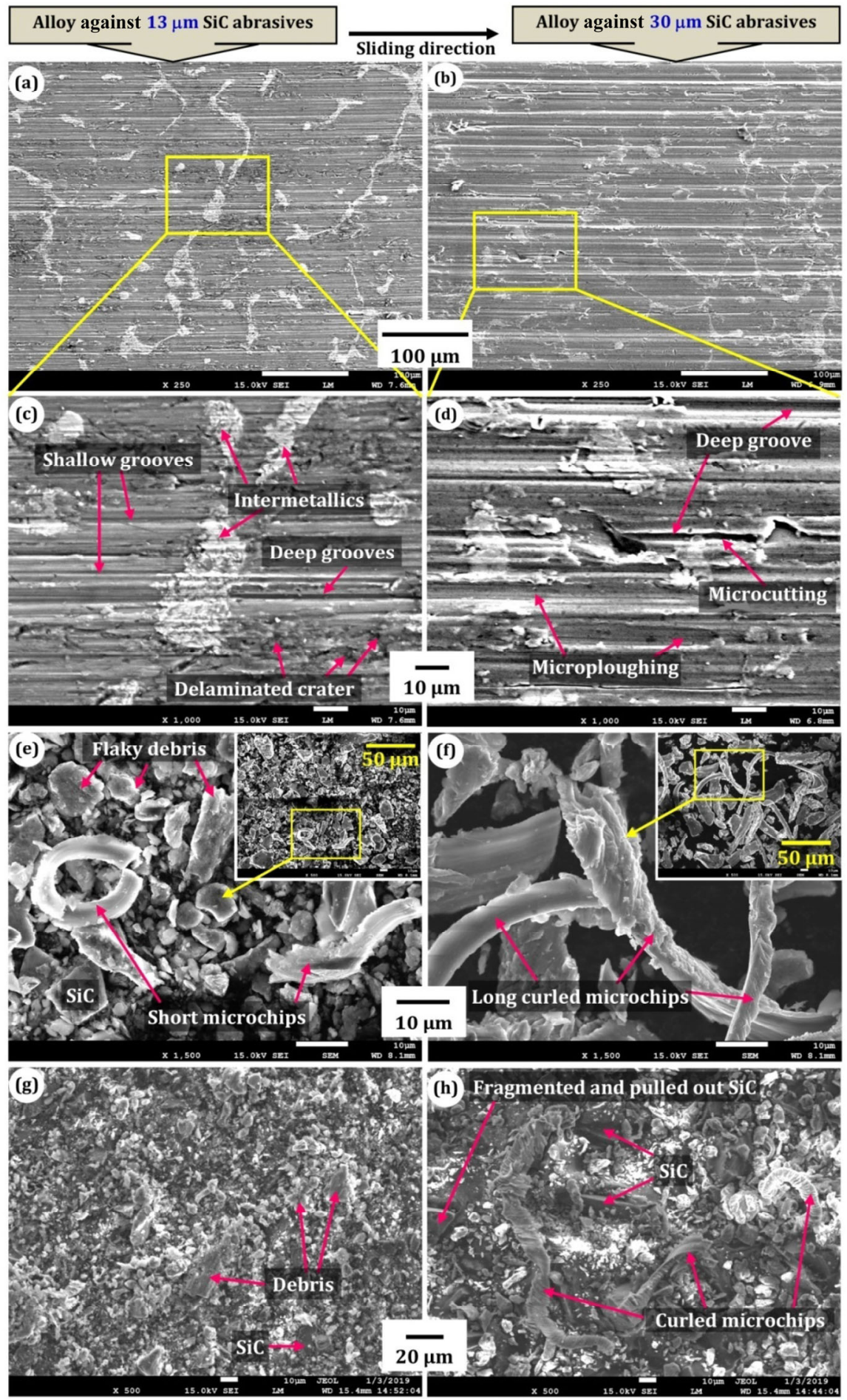

Fig. 3 FE SEM images illustrating the effects of size of SiC abrasives on the characteristics of abraded surfaces (a-d), generated debris $(\mathrm{e}-\mathrm{f})$, and abraded $\mathrm{SiC}$ emery papers $(\mathrm{g}-\mathrm{h})$ for unreinforced alloy under $40 \mathrm{~N}$ load, $20 \mathrm{~m}$ sliding distance, and $0.5 \mathrm{~m} \cdot \mathrm{s}^{-1}$ sliding velocity.

rubbed against the smallest $\mathrm{SiC}$ abrasive. Apart from the presence of deep continuous grooves on the worn surface of the composite, caused by microcutting and microploughing mechanisms due to abrasion specifically against 30- $\mu \mathrm{m}$ sized abrasives (Fig. 4(d)), the composite worn surfaces also consist of numerous micro-cracks and delaminated craters (Figs. 4(c) and 4(d)). The delamination mode of abrasive wear is a 

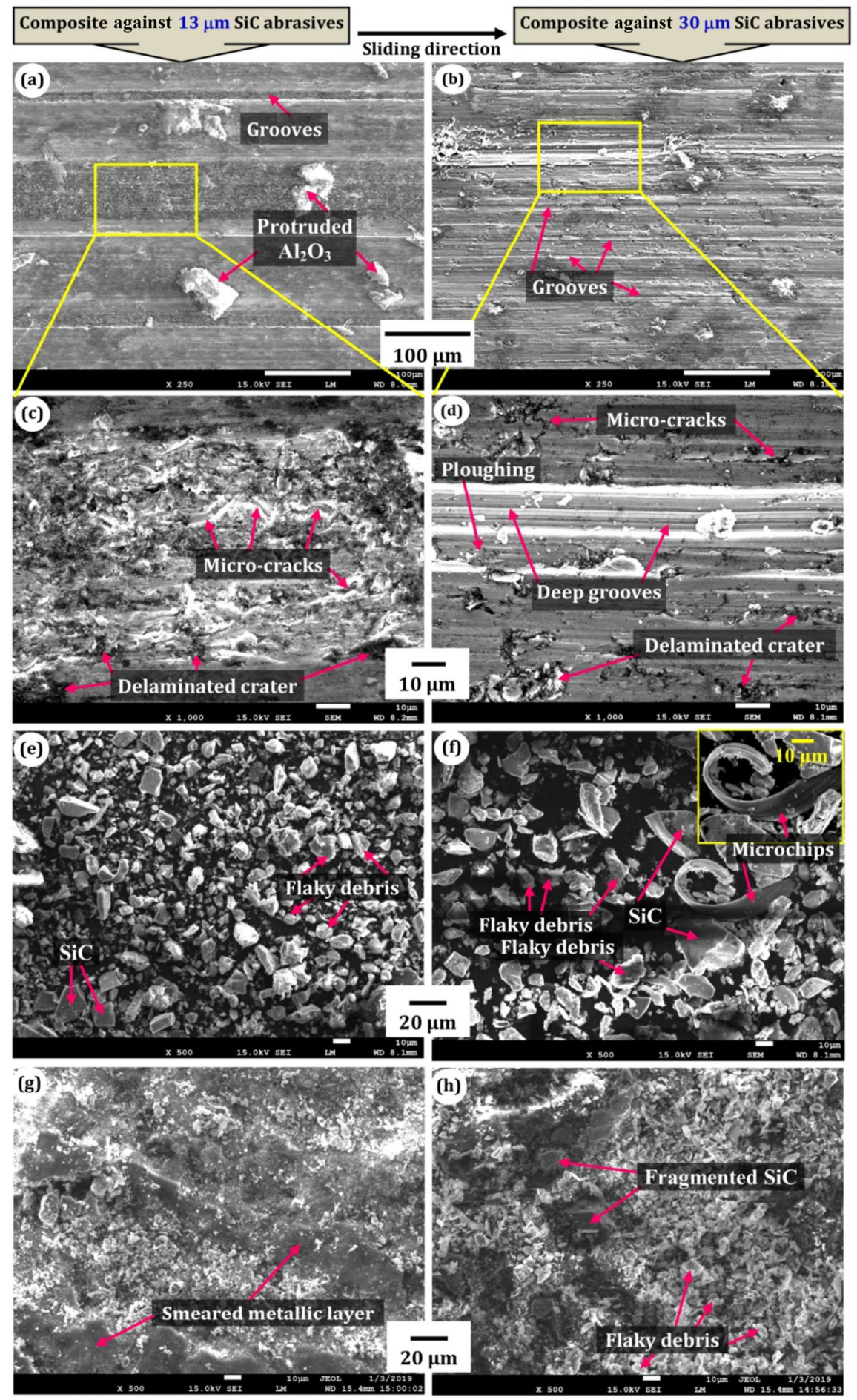

Fig. 4 FE SEM images illustrating the effects of size of SiC abrasives on the characteristics of worn surfaces (a-d), generated debris (e-f), and abraded SiC emery papers $(\mathrm{g}-\mathrm{h})$ for composite under the load of $40 \mathrm{~N}$, sliding distance of $20 \mathrm{~m}$, and sliding velocity of $0.5 \mathrm{~m} \cdot \mathrm{s}^{-1}$.

common phenomenon in the composite. It is developed due to microcracks, which originate and propagate in the sub-surface owing to the occurrence of microfatigue [66]. At the interfaces between reinforcing particles and the $\mathrm{Al}$ matrix, the chance of formation of crack nucleation is higher because of the distinct difference in mechanical properties between reinforcement and $\mathrm{Al}$ matrix. Moreover, reinforcing particles in the 

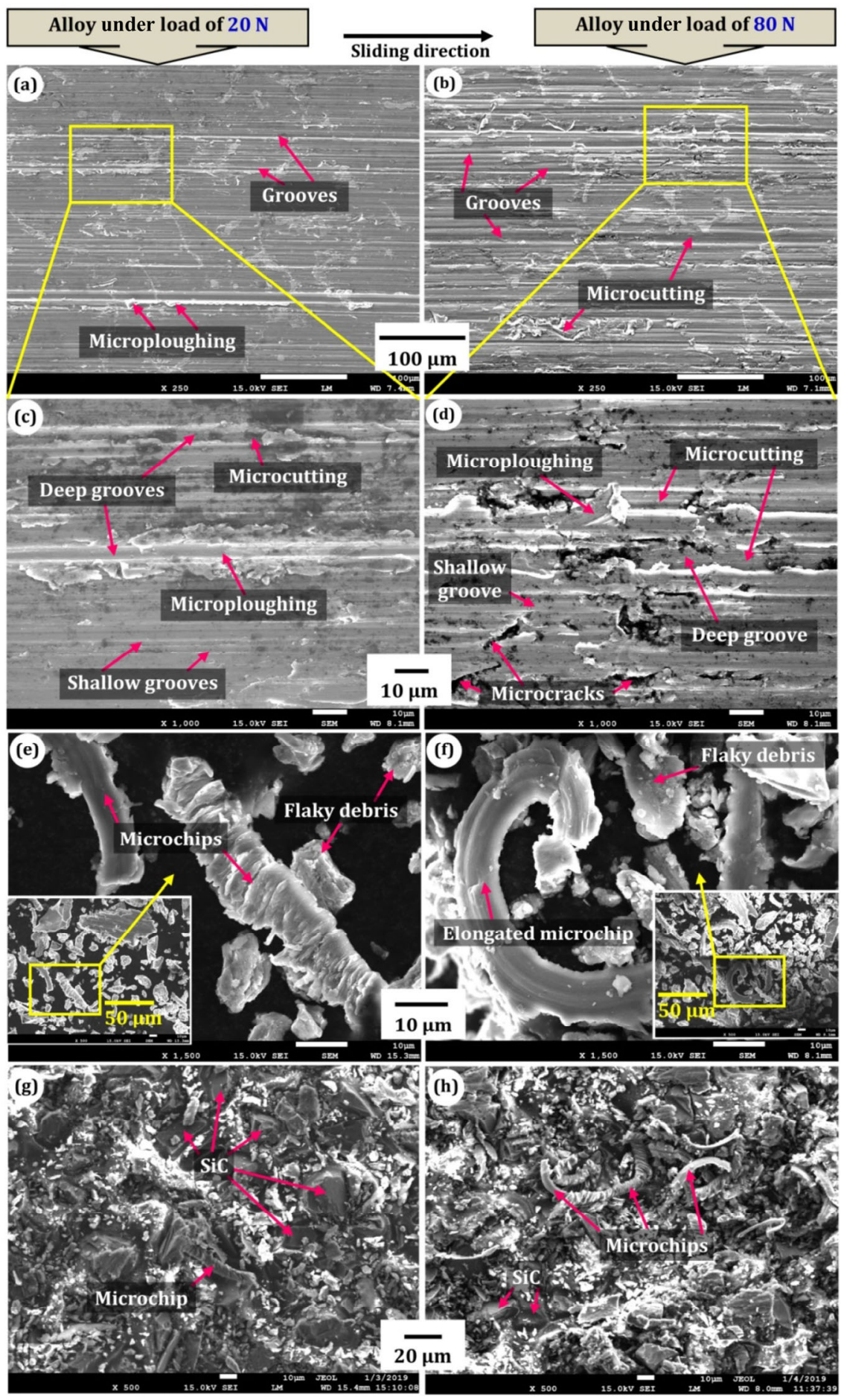

Fig. 5 FE SEM micrographs illustrating the effects of load on the characteristics of abraded surfaces (a-d), generated debris (e-f), and abraded SiC emery papers $(\mathrm{g}-\mathrm{h})$ for unreinforced alloy against $23 \mu \mathrm{m}$ sized $\mathrm{SiC}$ abrasives covering a sliding distance of $20 \mathrm{~m}$ with a velocity of $0.5 \mathrm{~m} \cdot \mathrm{s}^{-1}$.

Al matrix reduce ductility and toughness, and consequently cracks propagate easily in particle reinforced composites as compared to unreinforced matrix alloys [67]. In contrast to the base alloy (Figs. 3(e) and 3(f)), wear debris of the composite consists of mainly small, flaky and roughly equiaxed-shaped particles (Figs. 4(e) and $4(\mathrm{f})$ ), barring the presence of a few minute-sized microchips (Fig. 4(f)), which were generated only 

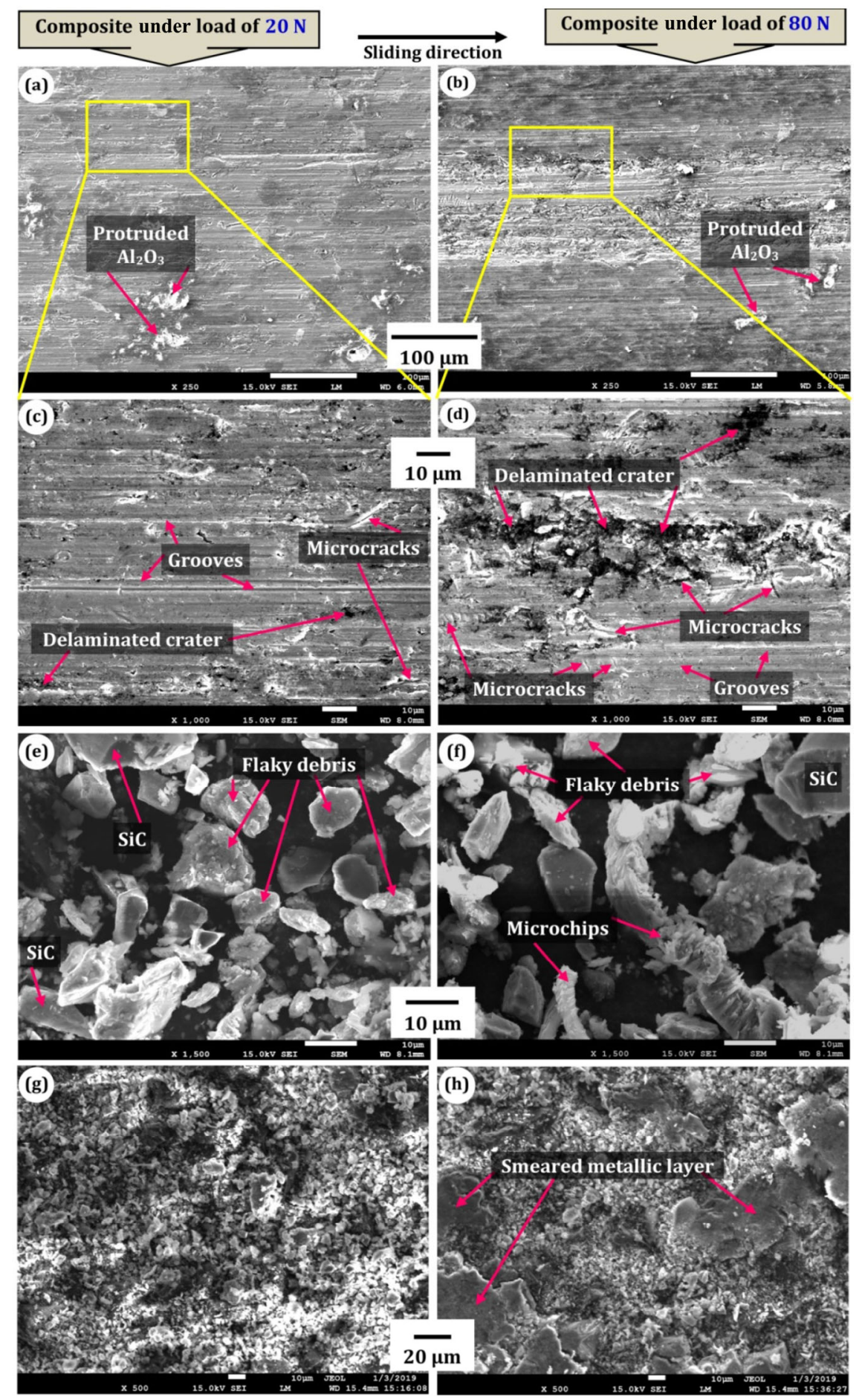

Fig. 6 FE SEM micrographs illustrating the effects of load on the characteristics of abraded surfaces (a-d), generated debris (e-f), and abraded $\mathrm{SiC}$ emery papers $(\mathrm{g}-\mathrm{h})$ for composite against $23 \mu \mathrm{m}$ sized $\mathrm{SiC}$ abrasives covering a sliding distance of $20 \mathrm{~m}$ with a velocity of $0.5 \mathrm{~m} \cdot \mathrm{s}^{-1}$.

against largest abrasives by microcutting and ploughing. The equiaxed flake-shaped particles in the wear debris of the composite are a characteristic of the delamination form of wear [64].
Distinctive differences are observed in abraded surfaces against the applied loads of 20 and $80 \mathrm{~N}$ for both the alloy and the composite. The worn surface of the base alloy under the application of $80 \mathrm{~N}$ load 
exhibits deeper and prominent grooves, clearly demonstrating signatures of microcutting and ploughing mechanisms, which are found less on the surface abraded under the $20 \mathrm{~N}$ load (Figs. 5(c) and 5(d)). Moreover, the wear debris of the alloy, generated under the applied load of $80 \mathrm{~N}$, yields lengthier and curvier microchips (Fig. 5(f)) as compared to those of shorter ones formed under the load of $20 \mathrm{~N}$ (Fig. 5(e)). The worn surface of composite under the load of $80 \mathrm{~N}$ is characterized by the presence of excessive amount of delaminated craters and microcracks (Figs. 6(b) and 6(d)). In contrast, the $20 \mathrm{~N}$ load produces a comparatively smoother surface with limited formation of craters and cracks (Figs. 6(a) and 6(c)). Apart from flaky particles, the wear debris of the composite under the load of $80 \mathrm{~N}$ consists of a few microchips (Fig. 6(f)), which are not found in the debris developed under the $20 \mathrm{~N}$ load (Fig. 6(e)).

Worn surfaces of the composite specimen are observed to be less affected by the penetration of $\mathrm{SiC}$ abrasives through the micro-mechanisms of cutting and ploughing. This may be attributed to the embedded $\mathrm{Al}_{2} \mathrm{O}_{3}$ reinforcing particles possessing greater hardness and wear resistance abilities than the matrix alloy [22]. Furthermore, no single $\mathrm{Al}_{2} \mathrm{O}_{3}$ particle is observed to be as pulled out, even in the magnified views of the FE SEM images of abraded composite surfaces, which illustrate a significant amount of interfacial bonding between reinforcements and the $\mathrm{Al}$ matrix. In case of the composite, ceramic reinforcements protruding from the matrix alloy result in a reduction of the real surface area of contact. Consequently, the degree of penetration of abrasives into the $\mathrm{Al}$ matrix diminishes leading to lesser removal of material, and thus an improvement in the wear resistance property $[17,65]$.

Morphologies of the abraded emery papers are also examined under FE SEM, and some selected images are depicted in Figs. 3-6. Compared with the largest $\mathrm{SiC}$ abrasive $(30 \mu \mathrm{m})$, the elongated curled microchips are attached to worn out emery paper, indicating the prevalence of the microcutting mechanism for the base alloy (Fig. 3(h)). Meanwhile, the attached debris largely consists of flaky metallic particles emphasizing the delamination mode of wear for the composite (Fig. 4(h)). With increasing load, microchips tend to become larger both in size and quantity in the debris of the base alloy observed from respective abraded papers (Figs. 5(g) and 5(h)). However, in case of the composite, at the greatest magnitude of load $(80 \mathrm{~N})$ and also against the smallest sized $\mathrm{SiC}$ abrasive $(13 \mu \mathrm{m})$, a smeared metallic layer is observed on abraded emery papers (Figs. $6(\mathrm{~h})$ and $4(\mathrm{~g})$ ). This may occur due to excessive debris accumulation/clogging in-between blunt and fractured abrasives [68]. Fractured and fragmented abrasives, which are indicative of highstress abrasion are observed on abraded papers for both the alloy and composite (Figs. 3(h) and 4(h)) [24, 45].

In brief, it may be concluded that microcutting and microploughing are the two predominant abrasion mechanisms for the unreinforced alloy, whereas delamination is the main mechanism for the composite with a limited degree of microploughing and microcutting.

\subsection{Enhancement of tribological performance of composite with respect to base alloy}

\subsubsection{Reduction of wear rate}

The tabulated test results in Table 3 show that the lowest value (i.e., $30.2 \%$ ) of $\Delta W R$ corresponds to the test No. 7, wherein the magnitude of load is lowest at $20 \mathrm{~N}$, and the abrasive size is highest at $30 \mu \mathrm{m}$. The highest value of $\Delta \mathrm{WR}$ is obtained as $81.9 \%$ under the test condition of highest magnitude of load $(80 \mathrm{~N})$ and a median abrasive size of $23 \mu \mathrm{m}$ (test No. 22). The effect of four control factors, each at three levels of the response variable (output), has been analyzed by the $\mathrm{S} / \mathrm{N}$ response table (Table 4 ). The magnitude of delta (defined as the difference between the maximum and minimum $\mathrm{S} / \mathrm{N}$ ratio values) in the table determines the influence of the factor on the quality characteristic of a response. The larger value of delta of a factor implies that the factor has higher influence on that response characteristic. The factor with highest delta value is assigned the rank 1 , exhibiting the greatest influence on the response variable (output). The largest value of delta (2.89) is possessed by the factor abrasive size followed by load (2.49), sliding velocity (1.22), and distance (0.60).

The main effect plots of means of $\Delta W R$ in Fig. 7(a) show that the factors' load and abrasive size have a considerable effect on $\Delta \mathrm{WR}$, which increases with increasing magnitudes of load, whereas the effect decreases with an increase in abrasive size. In 
Table 4 Response tables for $\mathrm{S} / \mathrm{N}$ ratios (larger is better).

\begin{tabular}{|c|c|c|c|c|c|c|c|c|}
\hline \multicolumn{5}{|c|}{$\%$ Variation in wear rates $(\Delta \mathrm{WR})$} & \multicolumn{4}{|c|}{$\%$ Variation in COF values $(\Delta \mathrm{COF})$} \\
\hline Level & Load $(\mathrm{N})$ & Abrasive size $(\mu \mathrm{m})$ & Distance $(\mathrm{m})$ & Velocity $\left(\mathrm{m} \cdot \mathrm{s}^{-1}\right)$ & Load $(\mathrm{N})$ & Grit (m) & Distance $(\mathrm{m})$ & Velocity $\left(\mathrm{m} \cdot \mathrm{s}^{-1}\right)$ \\
\hline 1 & 34.95 & 37.38 & 35.99 & 35.74 & 26.26 & 29.04 & 27.04 & 26.77 \\
\hline 2 & 36.65 & 37.16 & 36.59 & 36.34 & 27.76 & 28.62 & 27.47 & 27.48 \\
\hline 3 & 37.44 & 34.49 & 36.45 & 36.96 & 27.90 & 24.26 & 27.41 & 27.67 \\
\hline Delta & 2.49 & 2.89 & 0.60 & 1.22 & 1.65 & 4.78 & 0.43 & 0.90 \\
\hline Rank & 2 & 1 & 4 & 3 & 2 & 1 & 4 & 3 \\
\hline
\end{tabular}
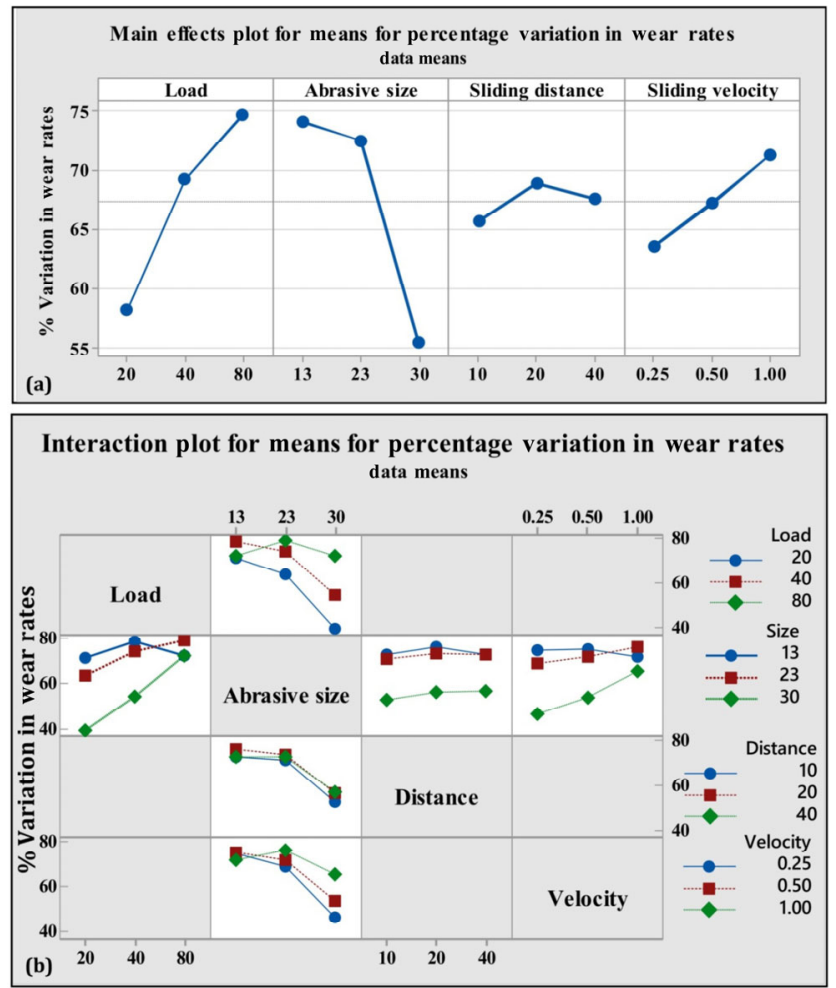

Fig. 7 (a) Main effects plots for means and (b) interaction plots of percentage variation in wear rates between alloy and composite, abbreviated as $\Delta \mathrm{WR}$ in the present study.

comparison to the factors load and abrasive size, the effect of the sliding velocity is moderate, while the effect of the distance on $\triangle \mathrm{WR}$ is almost insignificant. Earlier reports claim that wear rates of both alloy and composite materials are almost constant with respect to the sliding distance [21, 27]. The results of ANOVA, considering $\mathrm{S} / \mathrm{N}$ ratios of the $\Delta \mathrm{WR}$, are presented in Table 5. From the ANOVA table of $\Delta W R$ (Table 5), the statistically significant design parameters are found as load $(A)$, abrasive size $(B)$, sliding velocity $(D)$, interaction between $\mathrm{AB}$, and interaction between $\mathrm{BD}$. Among all the design parameters, the abrasive size dominates, contributing $39.3 \%$ alone to the $\Delta \mathrm{WR}$. The other important contributors are the load, contributing as $24.6 \%$, the velocity $(5.6 \%)$, and interactions of $\mathrm{AB}$ (18.4\%) and BD (8.3\%). A number of studies reported that the abrasive size factor greatly influences the tribological property of wear rate of AMCs [7, 15, 27]. For an example, the contribution of abrasive grain size is observed to be as great as $81.6 \%$ by Şahin [27] in two-body abrasive wear of $\mathrm{Al} 2014 / \mathrm{SiC}$ composites. Furthermore, factors like load and sliding distance are reported to be insignificant. The degree of dominance of abrasive size on the wear behavior varies for the alloy and the composite. Modi et al. [69] claimed that load is the most dominant factor influencing the abrasive wear rate of the $\mathrm{Zn}-\mathrm{Al}$ alloy, however the influence of abrasive size is supreme in case of the $\mathrm{Zn}-\mathrm{Al} / \mathrm{Al}_{2} \mathrm{O}_{3}$ composite. In a similar demonstration by Sahin and Özdin [15], the authors reported that the load effect is the most pronounced in two-body abrasion of the Al 2011 alloy, followed by the abrasive size, while the opposite holds true for the Al 2011/SiC composite. However, Mondal et al. [4] have indicated that effect of the load is more prominent than the abrasive size with regards to wear rates of both $\mathrm{ADC} 12 / \mathrm{Al}_{2} \mathrm{O}_{3}$ composites and their matrix alloy. From the ANOVA table (Table 5), the obtained values of the statistical measures of $R-S q$ and $R-S q$ (adjusted) are found to be 0.988 and 0.946 , respectively, inferring a good amount of correlation between the design model and the actual test results. Parallel lines in an interaction plot imply no effect regarding the interaction between two factors on the response output [46]. The presence of intersecting lines for the interactions of load-abrasive size $(\mathrm{AB})$ and abrasive size-velocity (BD), depicts the existence of interacting effects pertaining to these combinations of factors on $\Delta W R$ (Fig. 7(b)). 
Table 5 ANOVA tables based on $\mathrm{S} / \mathrm{N}$ ratios of outputs.

\begin{tabular}{|c|c|c|c|c|c|c|c|c|c|c|c|}
\hline \multicolumn{7}{|c|}{$\%$ Variation in wear rates $(\Delta \mathrm{WR})$} & \multicolumn{5}{|c|}{$\%$ Variation in $\mathrm{COF}$ values $(\Delta \mathrm{COF})$} \\
\hline Source & $\mathrm{DF}$ & Seq. SS & Adj. MS & $F_{\text {ratio }}$ & P-value & $\mathrm{P}(\%)$ & Seq. SS & Adj. MS & $F_{\text {ratio }}$ & P-value & $\mathrm{P}(\%)$ \\
\hline Load $(\mathrm{N})$ & 2 & 29.167 & 14.5833 & 59.13 & 0.000 & 24.56 & 14.953 & 7.4765 & 3.23 & 0.112 & 6.23 \\
\hline Abrasive size $(\mu \mathrm{m})$ & 2 & 46.666 & 23.3331 & 94.61 & 0.000 & 39.29 & 126.129 & 63.0644 & 27.25 & 0.001 & 52.56 \\
\hline Distance $(\mathrm{m})$ & 2 & 1.791 & 0.8956 & 3.63 & 0.093 & 1.51 & 0.988 & 0.4942 & 0.21 & 0.814 & 0.41 \\
\hline Velocity $\left(\mathrm{m} \cdot \mathrm{s}^{-1}\right)$ & 2 & 6.689 & 3.3446 & 13.56 & 0.006 & 5.63 & 4.075 & 2.0376 & 0.88 & 0.462 & 1.70 \\
\hline Load*grit $(\mathrm{N})$ & 4 & 21.825 & 5.4562 & 22.12 & 0.001 & 18.38 & 65.656 & 16.4139 & 7.09 & 0.019 & 27.36 \\
\hline Grit*distance (m) & 4 & 1.326 & 0.3316 & 1.34 & 0.355 & 1.12 & 2.181 & 0.5453 & 0.24 & 0.908 & 0.91 \\
\hline Grit*velocity $\left(\mathrm{m} \cdot \mathrm{s}^{-1}\right)$ & 4 & 9.83 & 2.4575 & 9.96 & 0.008 & 8.28 & 12.11 & 3.0276 & 1.31 & 0.365 & 5.05 \\
\hline Error & 6 & 1.48 & 0.2466 & & & 1.25 & 13.888 & 2.3147 & & & 5.79 \\
\hline \multirow[t]{2}{*}{ Total } & 26 & 118.774 & & & & 100.00 & 239.98 & & & & 100.00 \\
\hline & & $R-S q=0.98$ & $75 \quad R-S q$ & $\operatorname{adj})=($ & 460 & & $\mathrm{~S}=1.5214$ & $R-S q=$ & .9421 & $R-S q$ (adj) & $=0.7492$ \\
\hline
\end{tabular}

DF: degree of freedom; Seq. SS: sequential sum of squares; Adj. MS: adjusted sum of squares; $F$ : variance ratio; $\mathrm{P}(\%)$ : percentage of contribution.

The interacting effects between a pair of factors on $\Delta \mathrm{WR}$ in the form of surface plots are presented in Fig. 8, considering all combinations of the factors. Surface plots together with contour lines are generated by the Design Expert Software (Version 11). For any combination of two factors, the percentage variation of wear rates between alloy and composite, abbreviated as $\Delta \mathrm{WR}$, generally rises with extreme test parameters, i.e., with increased load, sliding distance, and velocity; whereas it diminishes with abrasive size. Apart from the interaction between the sliding distance and velocity (Fig. 8(f)), surface topographies for all other interactions of factors change considerably with respect to abscissa and coordinate values (Figs. 8(a)-8(e)).

\subsubsection{Reduction of coefficient of friction}

The $\mathrm{S} / \mathrm{N}$ response table of $\Delta \mathrm{COF}$ in Table 4 reveals that similarly to the condition of $\Delta \mathrm{WR}$, greatest value of delta, i.e., 4.78 corresponds to abrasive size. However, delta values of other factors like load (1.65), and sliding velocity (0.90) are much smaller compared to that of abrasive size, indicating the clear dominance of abrasive size on $\triangle \mathrm{COF}$. As with $\triangle \mathrm{WR}$, the lowest value of delta (0.43) also corresponds to the sliding distance. Based on the main effects plots of means for $\triangle \mathrm{COF}$ in Fig. 9(a), the values of $\triangle \mathrm{COF}$ are found to decrease sharply with an increase in abrasive size. There is an upward trend in the values of $\triangle \mathrm{COF}$ for the increase in load from 20 to $40 \mathrm{~N}$ and increase in sliding velocity from 0.25 to $0.5 \mathrm{~m} \cdot \mathrm{s}^{-1}$. However, there is a marginal
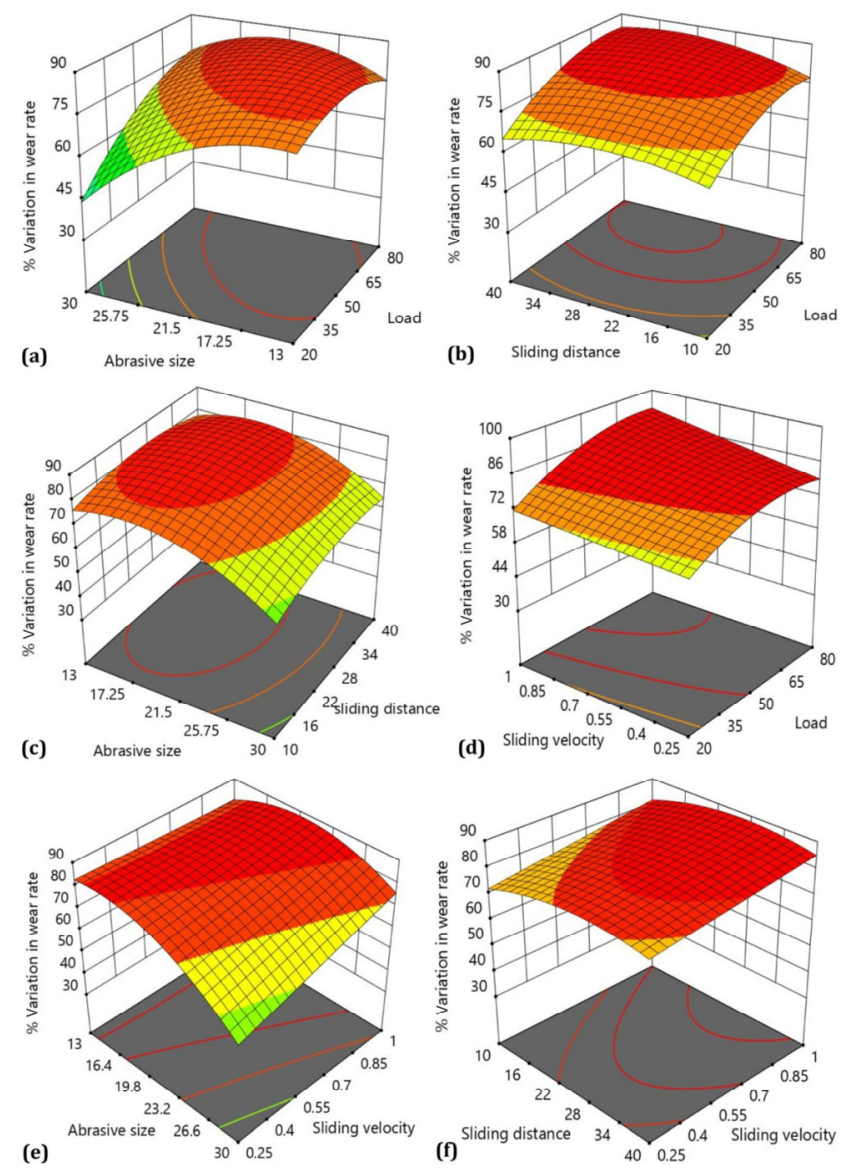

Fig. 8 Surface plots for the $\Delta W R$ with respect to (a) abrasive size $(\mu \mathrm{m})$ and load $(\mathrm{N}),(\mathrm{b})$ sliding distance $(\mathrm{m})$ and load $(\mathrm{N})$, (c) abrasive size $(\mu \mathrm{m})$ and sliding distance $(\mathrm{m})$, (d) sliding velocity $\left(\mathrm{m} \cdot \mathrm{s}^{-1}\right)$ and load $(\mathrm{N}),(\mathrm{e})$ abrasive size $(\mu \mathrm{m})$ and sliding velocity $\left(\mathrm{m} \cdot \mathrm{s}^{-1}\right)$, and (f) sliding distance $(\mathrm{m})$ and sliding velocity $\left(\mathrm{m} \cdot \mathrm{s}^{-1}\right) . \Delta \mathrm{WR}$ depicts percentage variation in wear rates between alloy and composite. 

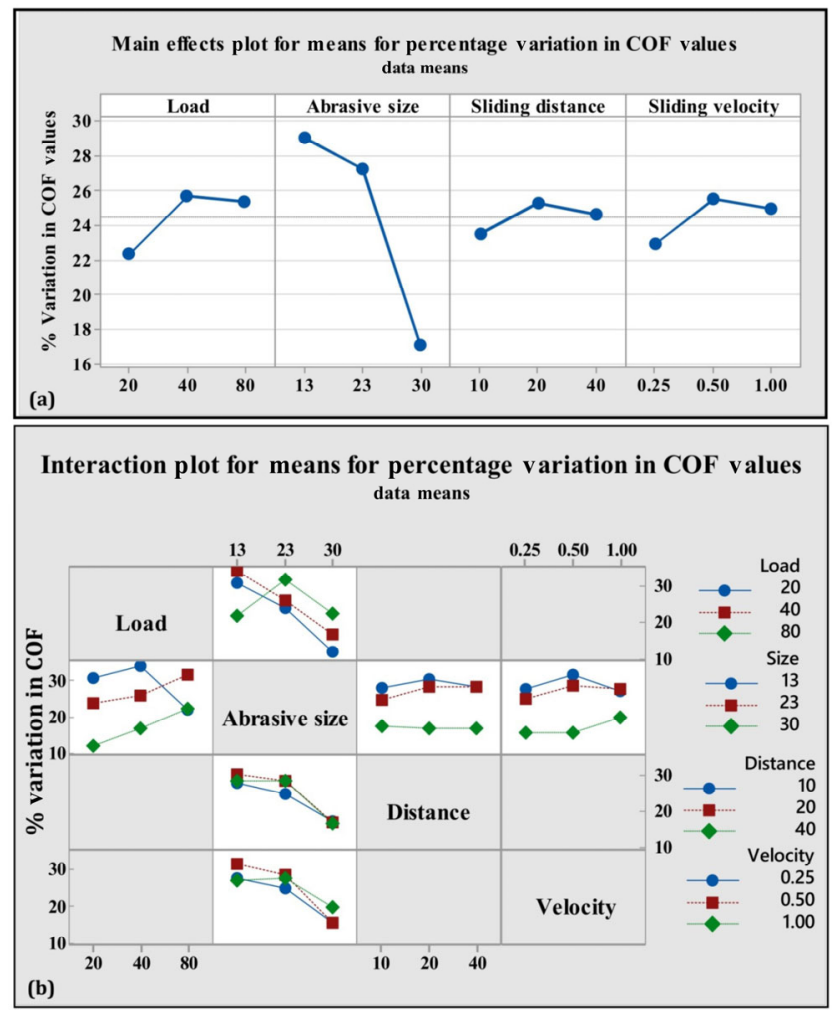

Fig. 9 (a) Main effects plots for means and (b) interaction plots of percentage variation in coefficients of friction between alloy and composite, abbreviated as $\triangle \mathrm{COF}(\%)$ in the present study.

fall observed in $\triangle \mathrm{COF}$ values beyond a load of $40 \mathrm{~N}$ and a velocity of $0.5 \mathrm{~m} \cdot \mathrm{s}^{-1}$. The sliding distance does not have any practical influence on $\triangle \mathrm{COF}$ (Fig. 9(a)). Considering $\mathrm{S} / \mathrm{N}$ ratios of the output characteristic, ANOVA results of the $\triangle \mathrm{COF}$ are compiled in Table 5. The statistically significant parameters with p-values $<0.05$ are found only as the abrasive size and interaction of load-abrasive size $(\mathrm{AB})$. With respect to $\triangle \mathrm{COF}$, the abrasive size is the predominant control factor with a percent contribution of $52.56 \%$; whereas the interaction of $\mathrm{AB}$ contributes a reasonable amount of $27.36 \%$. The correlation coefficients, $R-S q$ and $R-S q$ (adjusted), obtained as 0.942 and 0.749 , respectively, depict a sufficient amount of correlation between the developed mathematical model and experimental outcome.

From the interaction plots amongst the combinations of $A B, B C$, and $B D$ in Fig. 9(b), interacting effects are found to be almost insignificant except for the interaction between load and abrasive size $(A B)$. The interaction plot of $\mathrm{AB}$ consists of intersecting lines deducing its physical significance on $\triangle \mathrm{COF}$. Three dimensional surface plots of $\Delta \mathrm{COF}$, along with contour lines, are generated in Fig. 10 considering all the interactions between the four factors. The surface plots imply that the value of $\triangle \mathrm{COF}$ rises with increasing magnitudes of load, sliding distance, and velocity, as well as with the reduced size of abrasives. The variation in surface topographies of $\triangle \mathrm{COF}$ is noticeable mainly for the interactions of the abrasive size-load (Fig. 10(a)), abrasive size-distance (Fig. 10(c)), and abrasive sizevelocity (Fig. 10(e)), since the size of abrasives dominates the response characteristic of $\triangle \mathrm{COF}$.

\subsection{Selection of applicable wear conditions of composite material}

\subsubsection{Identification of wear conditions}

Changes in values of $\triangle \mathrm{WR}$ and $\triangle \mathrm{COF}$ in individual experiments are graphically illustrated in Fig. 11. The values of both $\triangle W R$ and $\triangle C O F$ are always preferred to be as great as possible, since the aim is to maximize the tribological performance of composite material over its matrix alloy for a given test condition. Hence, the selection of test conditions should be followed in such way that the composite would exhibit superior tribological performances compared to the unreinforced alloy, rendering $\triangle \mathrm{WR}$ and $\triangle \mathrm{COF}$ values closer to $100 \%$. The preferred target level is set to $\geq 50 \%$ for $\Delta \mathrm{WR}$ and $\geq 25 \%$ for $\triangle \mathrm{COF}$ for the identification of suitable test conditions. In Fig. 11, the preferred region for the use of composite material in view of attaining considerable improvements in tribological performances, has been marked in green. The optimum test condition for the selection of composite material over base alloy is identified corresponding to experiment No.11, among other preferable experiment Nos. 2 and 24. Hence, the intermediate level of applied load and the lowest abrasive size provide optimum tribological performance of the composite over the base alloy. Following the contour plots in Fig. 12, the regions corresponding to the maximum gains in $\Delta \mathrm{WR}$ and $\Delta C O F$ are illustrated separately. The contour plots of $\triangle W R$ and $\triangle C O F$ in uncoded form of factors are based on full quadratic response surface equations, which are specified as follows:

$\Delta \mathrm{WR}=58.4+0.072 A+1.990 \mathrm{~B}+0.861 C-35.5 D-$ $0.00695 A^{2}-0.1344 B^{2}-0.02147 C^{2}-0.6 D^{2}+0.03146 \mathrm{~A}^{*} \mathrm{~B}+$ $0.00333 A^{*} C+0.222 A^{*} D+0.00932 B^{*} C+1.716 B^{*} D$ 

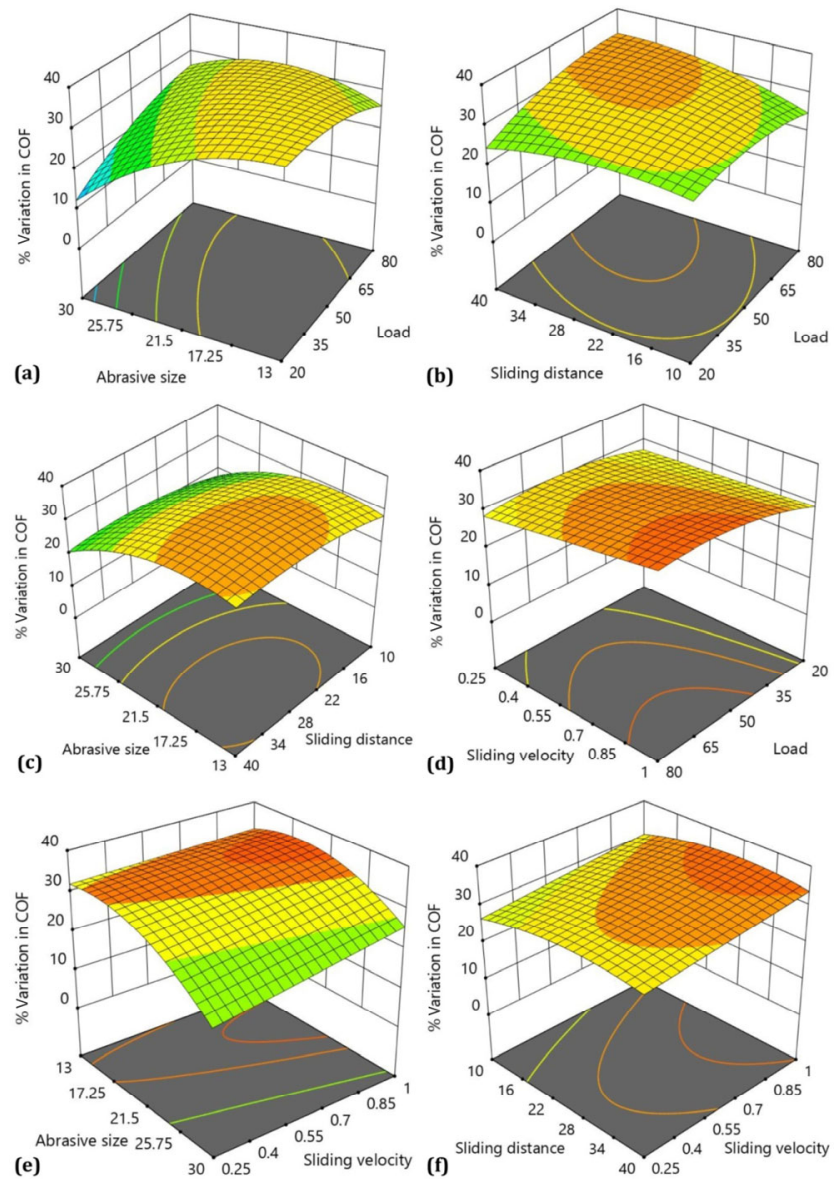

Fig. 10 Surface plots for the $\triangle \mathrm{COF}$ with respect to (a) abrasive size $(\mu \mathrm{m})$ and load $(\mathrm{N}),(\mathrm{b})$ sliding distance $(\mathrm{m})$ and load $(\mathrm{N})$, (c) abrasive size $(\mu \mathrm{m})$ and sliding distance $(\mathrm{m}),(\mathrm{d})$ sliding velocity $\left(\mathrm{m} \cdot \mathrm{s}^{-1}\right)$ and load $(\mathrm{N}),(\mathrm{e})$ abrasive size $(\mu \mathrm{m})$ and sliding velocity $\left(\mathrm{m} \cdot \mathrm{s}^{-1}\right)$, and (f) sliding distance $(\mathrm{m})$ and sliding velocity $\left(\mathrm{m} \cdot \mathrm{s}^{-1}\right)$. $\Delta \mathrm{COF}$ depicts percentage variation in coefficients of friction between alloy and composite.

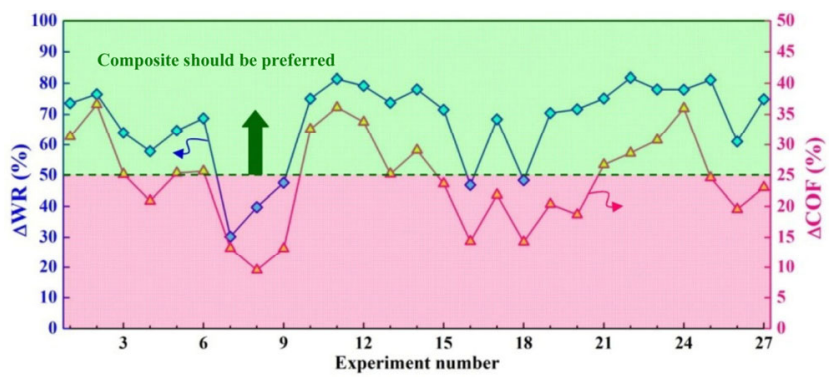

Fig. 11 Variations of $\triangle \mathrm{WR}$ and $\triangle \mathrm{COF}$ with respect to 27 experiments.

$\Delta \mathrm{COF}=42.7-0.0178 A+0.097 B+0.0249 C-30 D-$ $0.000003 A^{2}-0.001042 B^{2}-0.000049 C^{2}+0.000 D^{2}+$ $0.000082 \mathrm{~A}^{*} \mathrm{~B}+0.000014 \mathrm{~A}^{*} \mathrm{C}+0.0087 \mathrm{~A}^{*} \mathrm{D}-$ $0.000002 B^{*} C+0.151 B^{*} D$
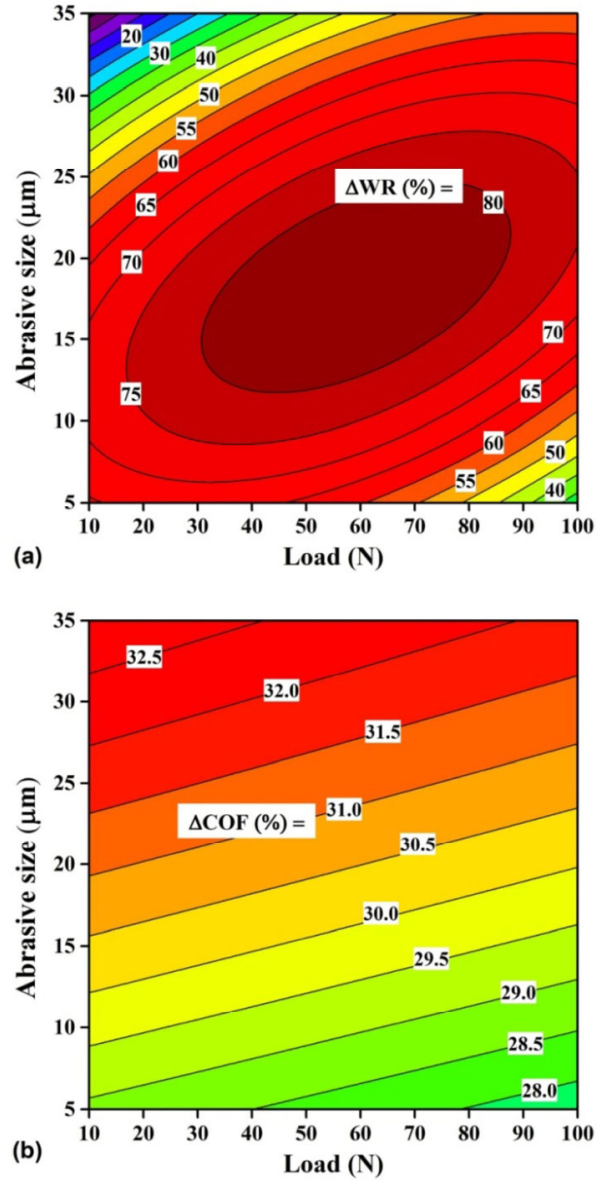

Fig. 12 Contour plots showing variations of (a) $\Delta \mathrm{WR}$ and (b) $\Delta \mathrm{COF}$ with respect to abrasive size $(\mu \mathrm{m})$ and load $(\mathrm{N})$.

where $A, B, C$, and $D$ are the load, abrasive size, sliding distance, and velocity, respectively. Moreover, $A^{*} B$, $A^{*} C, A^{*} D, B^{*} C$ and $B^{*} D$ denote the interactions of the respective factors. From the contour plots (Fig. 12), a suitable performance in $\triangle W R$ and $\triangle C O F$ can be achieved for loads varying from 35 to $45 \mathrm{~N}$ and abrasive sizes varying from 13 to $20 \mu \mathrm{m}$.

\subsubsection{Modelling of wear conditions and their validation}

Linear regression equations have been derived for studying relationships between control factors and response variables of $\Delta \mathrm{WR}$ and $\triangle \mathrm{COF}$, considering a $95 \%$ confidence. Based on the full quadratic (second order) regression equations, statistical models are generated in Table 6 with the help of Design Expert Software, assuming the variation of factors is continuous $[70,71]$. These prediction models in the coded form of factors are compiled in Table 6 along with correlation coefficients of $R-S q$ and $R-S q$ (adjusted). A correlation 
coefficient (say $R-S q$ ), with its value near 1, determines how close actual data points fit a plotted regression line $[53,72]$. The actual and predicted values of all 27 tests are compared in Fig. 13, wherein each and every 27 tests are marked separately with distinct symbols. A substantial amount of linearity between actual and predicted results (Fig. 13), and also, high values of correlation coefficients (Table 6) confirm the adequacy of both the models of $\triangle \mathrm{WR}$ and $\triangle \mathrm{COF}$ in actual tests.

Multi-response optimization technique with a combined desirability approach has been utilized to find the optimum tribological performance when a system comprises more than one response of interest (output variable) $[17,37]$. In this study, the combined optimization technique considering both $\triangle W R$ and $\triangle \mathrm{COF}$ has been performed employing the MINITAB software. The target values are set as maximum for both output characteristics of $\Delta \mathrm{WR}$ and $\triangle \mathrm{COF}$. The selective sets of control factors (test parameters) with combined desirability values are presented in Table 7 .
A desirability value near to 1 for a particular set of test parameters indicates that one is close to accomplishing the target. For validation, a confirmatory experiment has been further performed under the selective set of control factors satisfying the combined desirability value of 1 (solution No. 1 in Table 7). The obtained results of $\triangle \mathrm{WR}$ and $\triangle \mathrm{COF}$ are shown in Table 8 and compared with that of the predicted results as estimated in solution No. 1 of Table 7. The variations between predicted and experimental results up to a maximum of $9.69 \%$ have been evaluated, assuring good validation of the design model with real tests (Table 8 ).

Abraded surfaces and wear debris of the confirmatory experiment have also been studied to realize the intended performance of composite with a reference to the base alloy under the selected wear condition. The representative FE SEM images and EDX profiles are depicted in Fig. 14. The differences in abraded surfaces, as well as in the wear debris between the

Table 6 Characteristic models based on coded linear regression equations.

\begin{tabular}{|c|c|c|c|}
\hline $\begin{array}{l}\text { Variations in tribological } \\
\text { characteristics }\end{array}$ & Multiple linear regression equations & $R-S q$ & $R-S q(\operatorname{adj})$ \\
\hline$\Delta \mathrm{WR}$ & $\begin{array}{l}83.4668+8.0502 * A-7.7318 * B+2.1079 * C+4.3635 * D+8.0234 * \mathrm{AB}+ \\
1.5978 * \mathrm{AC}+2.1392 * \mathrm{AD}+1.1881 * \mathrm{BC}+5.4691 * \mathrm{BD}-0.3553 * \mathrm{CD}-5.9792 * A^{2}- \\
9.7081 * B^{2}-4.5537 * C^{2}\end{array}$ & 0.9768 & 0.9537 \\
\hline$\Delta \mathrm{COF}$ & $\begin{array}{l}32.6307+1.6552 * A-5.2308 * B+1.4587 * C+2.0949 * D+5.3293 * \mathrm{AB}+ \\
2.7584 * \mathrm{AC}+1.1152 * \mathrm{AD}-0.0340 * \mathrm{BC}+1.5368 * \mathrm{BD}+0.0201 * \mathrm{CD}-2.6204 * A^{2}- \\
5.4375 * B^{2}-2.4944 * C^{2}\end{array}$ & 0.8840 & 0.7680 \\
\hline
\end{tabular}

$A$ : load; $B$ : abrasive size; $C$ : sliding distance; $D$ : sliding velocity.

$\mathrm{AB}, \mathrm{AC}, \mathrm{AD}, \mathrm{BC}$, and $\mathrm{BD}$ are the interactions of the respective factors.

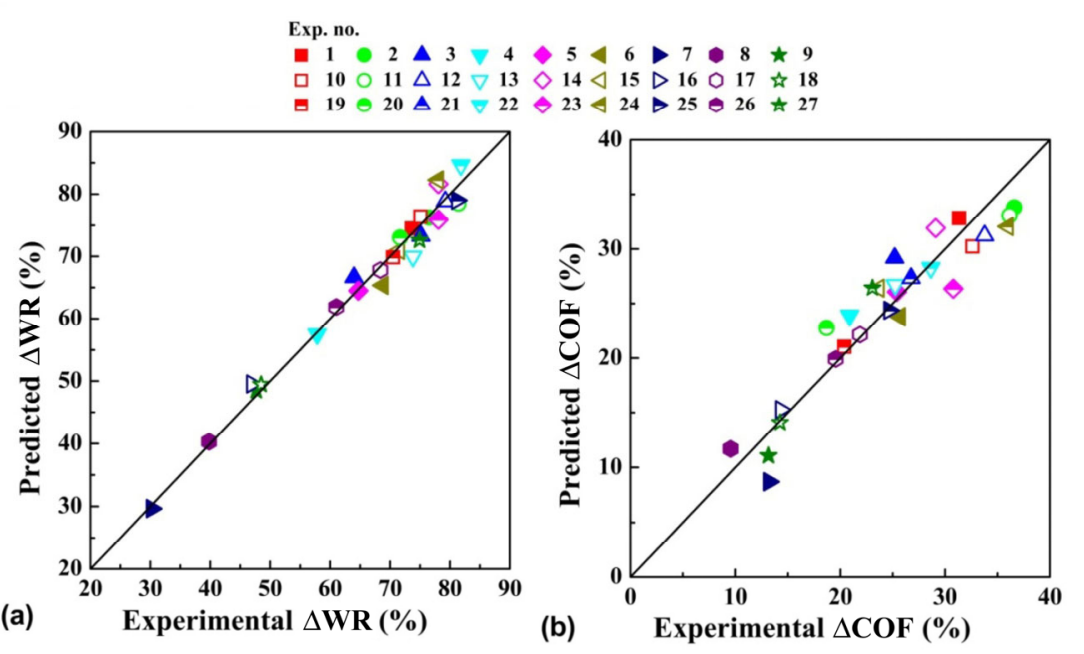

Fig. 13 Experimental vs. predicted values of (a) $\Delta W R$ and (b) $\triangle C O F$. 
Table 7 Optimized predicted testing parameters with target output values based on desirability approach.

\begin{tabular}{|c|c|c|c|c|c|c|c|}
\hline \multirow{2}{*}{$\begin{array}{c}\text { Solution } \\
\text { No. }\end{array}$} & \multicolumn{4}{|c|}{ Optimized predicted test condition } & \multicolumn{2}{|c|}{ Target values of responses } & \multirow{2}{*}{$\begin{array}{l}\text { Combined } \\
\text { desirability }\end{array}$} \\
\hline & Load $(\mathrm{N})$ & Abrasive size $(\mu \mathrm{m})$ & Sliding distance $(\mathrm{m})$ & Sliding velocity $\left(\mathrm{m} \cdot \mathrm{s}^{-1}\right)$ & $\Delta \mathrm{WR}(\%)$ & $\Delta \mathrm{COF}(\%)$ & \\
\hline 1 & 80 & 22.79 & 35.15 & 1.00 & 93.93 & 36.67 & 1.00 \\
\hline 2 & 34.44 & 19.21 & 23.26 & 1.00 & 81.84 & 33.89 & 0.97 \\
\hline 3 & 80 & 30 & 40 & 1.00 & 89.01 & 32.73 & 0.95 \\
\hline 4 & 77.73 & 14.87 & 39.36 & 1.00 & 81.17 & 32.32 & 0.94 \\
\hline 5 & 27.14 & 13 & 16.98 & 0.25 & 79.68 & 33.60 & 0.93 \\
\hline 6 & 35.03 & 15.98 & 16.82 & 0.94 & 79.54 & 33.65 & 0.93 \\
\hline 7 & 34.97 & 15.34 & 34.55 & 0.96 & 79.36 & 33.44 & 0.93 \\
\hline 8 & 30.21 & 13 & 34.40 & 0.25 & 79.93 & 32.68 & 0.93 \\
\hline
\end{tabular}

Note: target is set as maximum for each of the output responses. Weight and importance are set as $(1,1)$ for $\Delta \mathrm{COF}$, and $(1,2)$ for $\Delta \mathrm{WR}$, respectively in MINITAB.

Table 8 Variation between experimental and target values based on predicted test condition of desirability value 1.

\begin{tabular}{|c|c|c|c|c|c|c|c|}
\hline \multirow{2}{*}{ Solution No. } & \multirow{2}{*}{$\begin{array}{l}\text { Combined } \\
\text { desirability }\end{array}$} & \multicolumn{2}{|c|}{ Target output value } & \multicolumn{2}{|c|}{ Experimental output value } & \multicolumn{2}{|c|}{ Deviation $(\%)$} \\
\hline & & $\Delta \mathrm{WR}(\%)$ & $\Delta \mathrm{COF}(\%)$ & $\Delta \mathrm{WR}(\%)$ & $\Delta \mathrm{COF}(\%)$ & $\Delta \mathrm{WR}$ & $\Delta \mathrm{COF}$ \\
\hline 1 & 1.00 & 93.93 & 36.67 & 84.83 & 33.38 & 9.69 & 8.97 \\
\hline
\end{tabular}

alloy and composite are distinctly visible and marked (Fig. 14). The worn surface of alloy is characterized with the severity of microcutting-assisted formation of deep grooves and generation of deformation lips, which are both symbolic of considerable plastic deformation (Fig. 14(a)). In contrast, the worn surface of composite produces shallow grooves, micro-cracks, and delaminated craters (Fig. 14(b)). The debris of the alloy specimen is distinguished by the lengthy curlshaped microchips (Fig. 14(c)) opposed to the noticeably minute-sized microchip and flaky debris in case of the composite (Fig. 14(d)). With the help of EDX analyses, the presence of $\mathrm{SiC}$ abrasive (Fig. 14(f)) as well as the metallic material (Fig. 14(e)) are confirmed in the generated wear debris. These observations further establish the superior tribological performance of the composite, when wear conditions are selected judiciously.

\section{Conclusions}

The tribological performance of the $\mathrm{Al}-\mathrm{Zn}-\mathrm{Mg}-\mathrm{Cu} /$ $\mathrm{Al}_{2} \mathrm{O}_{3}$ composite material with respect to its matrix alloy pertaining to two-body abrasion has been studied in view of achieving improved wear resistance and a reduced COF following the Taguchi $\mathrm{L}_{27}$ orthogonal experimental layout. The experimental plan considers four control factors, each with three different levels. The comparative study of wear rate and COF between the alloy and composite is accomplished, employing ANOVA and full quadratic regression methodologies. Attempts are made to identify the suitable wear conditions where composite with reference to alloy should provide optimum improvement in tribological performance in terms of at least a $50 \%$ reduction in wear rate and a minimum of $25 \%$ lowering of the COF. To this end, a multi-response optimization technique with combined desirability approach is employed. In addition, the effects of dominant factors like abrasive size and load on abrasion mechanisms are studied separately for the alloy and composite through in depth microscopic characterizations of worn surfaces and generated wear debris. The following major conclusions can be drawn from the present study:

1) The selection of suitable processing parameters associated with the stir casting method ensures almost uniform distribution of reinforcing particles in the matrix of the Al- $\mathrm{Zn}-\mathrm{Mg}-\mathrm{Cu}$ alloy, as evidenced by optical and FE SEM examinations. The development of different intermetallics and the presence of $\mathrm{Al}_{2} \mathrm{O}_{3}$ reinforcing particles in cast materials are confirmed 

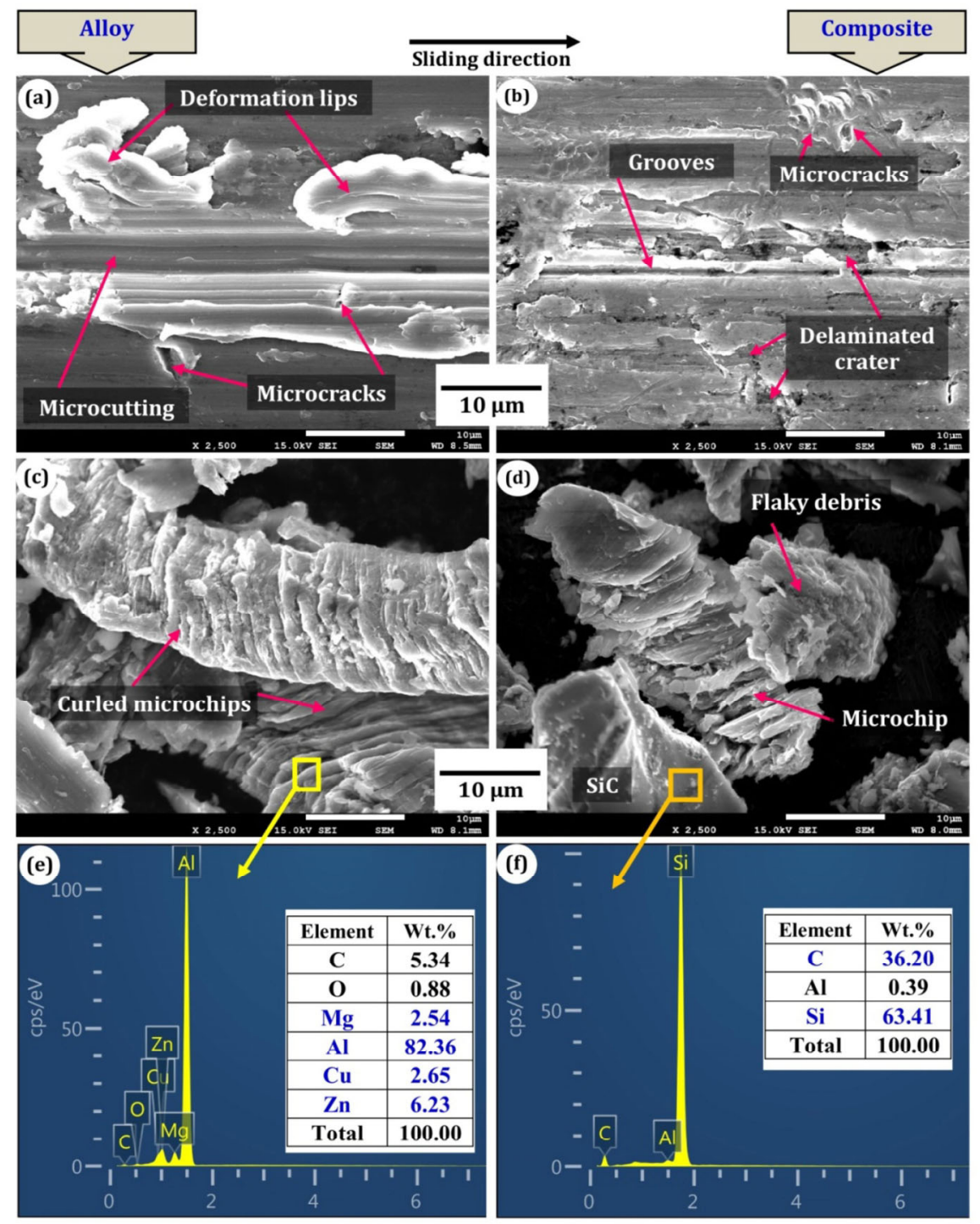

Fig. 14 FE SEM micrographs presenting abraded surfaces $(a-b)$ and generated wear debris ( $c-d)$ of alloy (a-c) and composite (b-d) under the condition of solution No. 1 in Table 7 obtained considering multi-response optimization technique. (e) and (f) present EDX profiles along with results of semi-quantitative elemental analyses corresponding to the marked areas in (c) and (d), respectively. Abrasion conditions were $80 \mathrm{~N}$ load, $23 \mu \mathrm{m} \mathrm{SiC}$ abrasive size, $35 \mathrm{~m}$ sliding distance, and $1.0 \mathrm{~m} \cdot \mathrm{s}^{-1}$ sliding velocity.

by EDX analyses. The prepared composite provides an improvement of around $26 \%$ in bulk hardness though a slightly higher porosity content over the unreinforced alloy.

2) Tribo-characterizations of alloy and composite infer that composite possesses significantly lower wear rate as well as reduced COF values under identical test condition. In general, the difference in wear rates between the alloy and composite increases with increasing severity of the wear condition i.e., with raising load and abrasive size. However, the highest difference in $\mathrm{COF}$ values corresponds to the higher load and an intermediate range of abrasive size.

3) Insight on the dominant roles of the load and abrasive size on two-body abrasion is achieved through detailed post-wear characterizations. Material loss during two-body abrasion occurs mainly by the mechanisms of microcutting and ploughing in case of the base alloy; however, this occurs predominantly by delamination for the composite.

4) The main effects plots of means reveal that the percent reduction in the wear rate $(\triangle W R)$ and $C O F$ $(\triangle \mathrm{COF})$ for the composite with reference to the 
unreinforced alloy are found to increase sharply with lowering of the abrasive size. The magnitude of $\Delta W R$ enhances with increase in load, whereas its influence on the improvement of $\triangle \mathrm{COF}$ is rather marginal. Apart from the modest influence of sliding velocity only on $\Delta W R$, no other considerable effects from sliding distance and velocity are noticeable.

5) Results of ANOVA infer that the abrasive size is the predominant one, contributing most to both response characteristics of $\triangle \mathrm{WR}$ and $\triangle \mathrm{COF}$. The subsequent dominating factor is found to be the load for $\triangle W R$ and the interaction of the load-abrasive size for $\triangle \mathrm{COF}$. The effect of sliding distance on both outputs of $\triangle W R$ and $\triangle C O F$ is insignificant.

6) The applicable wear condition for the developed composite with $\Delta \mathrm{WR} \geq 50 \%$ and $\Delta \mathrm{COF} \geq 25 \%$ has been identified as an intermediate level of load $(35-45 \mathrm{~N})$ and the lowest size $(13-20 \mu \mathrm{m}) \mathrm{SiC}$ abrasives. The multi-response optimization tool is employed for a combined optimization of $\Delta \mathrm{WR}$ and $\triangle \mathrm{COF}$ with target levels set as the maximum for both response characteristics. A confirmatory experiment is performed for validation of the design model, showing errors within $9.69 \%$.

7) Predictive models based on full quadratic regression equations for both $\triangle \mathrm{WR}$ and $\triangle \mathrm{COF}$ are generated and compared with experimental results. Developed mathematical models exhibit a good extent of linearity with the results of actual tests, yielding $R-S q$ values varying from 0.98 to 0.88 .

\section{Acknowledgements}

The authors recognize the support obtained from the Centre of Excellence on Microstructurally Designed Advanced Materials Development under TEQIP-II, IIEST Shibpur. The assistance granted from DST-FIST to set up Advanced Tribology Laboratory under the Department of Mechanical Engineering, IIEST Shibpur is also highly appreciated.

Open Access This article is licensed under a Creative Commons Attribution 4.0 International Li-cense, which permits use, sharing, adaptation, distribution and reproduction in any medium or for-mat, as long as you give appropriate credit to the original author(s) and the source, provide a link to the Creative Commons licence, and indicate if changes were made.

The images or other third party material in this article are included in the article's Creative Commons licence, unless indicated otherwise in a credit line to the material. If material is not in-cluded in the article's Creative Commons licence and your intended use is not permitted by statutory regulation or exceeds the permitted use, you will need to obtain permission directly from the copyright holder.

To view a copy of this licence, visit http:// creativecommons.org/licenses/by/4.0/.

\section{References}

[1] Mazahery A, Shabani M O. A356 reinforced with nanoparticles: Numerical analysis of mechanical properties. JOM 64(2): 323-329 (2012)

[2] Singh J. Fabrication characteristics and tribological behavior of $\mathrm{Al} / \mathrm{SiC} / \mathrm{Gr}$ hybrid aluminum matrix composites: A review. Friction 4(3): 191-207 (2016)

[3] Das S, Das S, Das K. Abrasive wear of zircon sand and alumina reinforced $\mathrm{Al}-4.5 \mathrm{wt} \% \mathrm{Cu}$ alloy matrix composites-A comparative study. Compos Sci Technol 67(3-4): 746-751 (2007)

[4] Mondal D P, Das S, Jha A K, Yegneswaran A H. Abrasive wear of $\mathrm{Al}$ alloy $-\mathrm{Al}_{2} \mathrm{O}_{3}$ particle composite: A study on the combined effect of load and size of abrasive. Wear 223(1-2): 131-138 (1998)

[5] Kumar P R S, Kumaran S, Rao T S, Natarajan S. High temperature sliding wear behavior of press-extruded AA6061/fly ash composite. Mater Sci Eng A 527(6): 1501-1509 (2010)

[6] Borgonovo C, Apelian D. Manufacture of aluminum nanocomposites: A critical review. Mater Sci Forum 678: 1-22 (2011)

[7] Kumar S, Balasubramanian V. Effect of reinforcement size and volume fraction on the abrasive wear behaviour of AA7075 $\mathrm{Al} / \mathrm{SiC}_{\mathrm{p}} \mathrm{P} / \mathrm{M}$ composites-A statistical analysis. Tribol Int 43(1-2): 414-422 (2010)

[8] Ahmed A, Neely A J, Shankar K, Nolan P, Moricca S, Eddowes T. Synthesis, tensile testing, and microstructural characterization of nanometric SiC particulate-reinforced Al 7075 matrix composites. Metall Mater Trans A 41(6): 1582-1591 (2010)

[9] Dursun T, Soutis C. Recent developments in advanced aircraft aluminium alloys. Mater Des 56: 862-871 (2014)

[10] Chawla N, Chawla K K. Metal-matrix composites in ground transportation. JOM 58(11): 67-70 (2006) 
[11] Miracle D B. Metal matrix composites-from science to technological significance. Compos Sci Technol 65(15-16): 2526-2540 (2005)

[12] Hassan S F, Gupta M. Effect of submicron size $\mathrm{Al}_{2} \mathrm{O}_{3}$ particulates on microstructural and tensile properties of elemental Mg. J Alloys Compd 457(1-2): 244-250 (2008)

[13] Rahimian M, Parvin N, Ehsani N. The effect of production parameters on microstructure and wear resistance of powder metallurgy $\mathrm{Al}-\mathrm{Al}_{2} \mathrm{O}_{3}$ composite. Mater Des 32(2): 1031-1038 (2011)

[14] Sardar S, Karmakar S K, Das D. Ultrasonic cavitation based processing of metal matrix nanocomposites: An overview. Adv Mater Res 1042: 58-64 (2014)

[15] Sahin Y, Özdin K. A model for the abrasive wear behaviour of aluminium based composites. Mater Des 29(3): 728-733 (2008)

[16] Suresha B, Siddaramaiah, Kishore, Seetharamu S, Kumaran P S. Investigations on the influence of graphite filler on dry sliding wear and abrasive wear behaviour of carbon fabric reinforced epoxy composites. Wear 267(9-10): 1405-1414 (2009)

[17] Kumar A, Mahapatra M M, Jha P K. Modeling the abrasive wear characteristics of in-situ synthesized $\mathrm{Al}-4.5 \% \mathrm{Cu} / \mathrm{TiC}$ composites. Wear 306(1-2): 170-178 (2013)

[18] Harsha A P, Tewari U S. Two-body and three-body abrasive wear behaviour of polyaryletherketone composites. Polym Test 22(4): 403-418 (2003)

[19] Sheu C Y, Lin S J. Particle size effects on the abrasive wear of $20 \mathrm{vol} \% \mathrm{SiC}_{\mathrm{p}} / 7075 \mathrm{Al}$ composites. Scr Mater 35(11): 1271-1276 (1996)

[20] Lin S J, Liu K S. Effect of aging on abrasion rate in an Al-Zn-Mg-SiC composite. Wear 121(1): 1-14 (1988)

[21] Das S, Mondal D P, Sawla S, Dixit S. High stress abrasive wear mechanism of LM13-SiC composite under varying experimental conditions. Metall Mater Trans A 33(9): 3031-3044 (2002)

[22] Kök M, Özdin K. Wear resistance of aluminium alloy and its composites reinforced by $\mathrm{Al}_{2} \mathrm{O}_{3}$ particles. J Mater Process Technol 183(2-3): 301-309 (2007)

[23] Wang A G, Hutchings I M. Wear of alumina fibre-aluminium metal matrix composites by two-body abrasion. Mater Sci Technol 5(1): 71-76 (1989)

[24] Deuis R L, Subramanian C, Yellup J M. Abrasive wear of aluminium composites - a review. Wear 201(1-2): 132-144 (1996)

[25] Roy R K. A Primer on the Taguchi Method. New York (USA): Van Nostrand Reinhold, 1990.

[26] Dehnad K. Quality Control, Robust Design, and the Taguchi Method. Boston (USA): Springer, 1989: 2015-2015.
[27] Şahin Y. Abrasive wear behaviour of SiC/2014 aluminium composite. Tribol Int 43(5-6): 939-943 (2010)

[28] Sardar S, Karmakar S K, Das D. Microstructure and tribological performance of alumina-aluminum matrix composites manufactured by enhanced stir casting method. $J$ Tribol 141(4): 041602 (2019)

[29] Hashim J, Looney L, Hashmi M S J. Particle distribution in cast metal matrix composites-part II. J Mater Process Technol 123(2): 258-263 (2002)

[30] Naher S, Brabazon D, Looney L. Simulation of the stir casting process. J Mater Process Technol 143-144: 567-571 (2003)

[31] Prabu S B, Karunamoorthy L, Kathiresan S, Mohan B. Influence of stirring speed and stirring time on distribution of particles in cast metal matrix composite. J Mater Process Technol 171(2): 268-273 (2006)

[32] Ezatpour H R, Sajjadi S A, Sabzevar M H, Huang Y Z. Investigation of microstructure and mechanical properties of Al6061-nanocomposite fabricated by stir casting. Mater Des 55: 921-928 (2014)

[33] Kok M. Production and mechanical properties of $\mathrm{Al}_{2} \mathrm{O}_{3}$ particle-reinforced 2024 aluminium alloy composites. $J$ Mater Process Technol 161(3): 381-387 (2005)

[34] Y1lmaz O, Buytoz S. Abrasive wear of $\mathrm{Al}_{2} \mathrm{O}_{3}$-reinforced aluminium-based MMCs. Compos Sci Technol 61(16): 2381-2392 (2001)

[35] Hashim J, Looney L, Hashmi M S J. Metal matrix composites: Production by the stir casting method. J Mater Process Technol 92-93: 1-7 (1999)

[36] Umanath K, Palanikumar K, Selvamani S T. Analysis of dry sliding wear behaviour of $\mathrm{Al} 6061 / \mathrm{SiC} / \mathrm{Al}_{2} \mathrm{O}_{3}$ hybrid metal matrix composites. Compos Part B Eng 53: 159-168 (2013)

[37] Yigezu B S, Mahapatra M M, Jha P K. On modeling the abrasive wear characteristics of in situ $\mathrm{Al}-12 \% \mathrm{Si} / \mathrm{TiC}$ composites. Mater Des 50: 277-284 (2013)

[38] Sardar S, Karmakar S K, Das D. Evaluation of abrasive wear resistance of $\mathrm{Al}_{2} \mathrm{O}_{3} / 7075$ composite by taguchi experimental design technique. Trans Indian Inst Met 71(8): 1847-1858 (2018)

[39] Rokni M R, Zarei-Hanzaki A, Abedi H R. Microstructure evolution and mechanical properties of back extruded 7075 aluminum alloy at elevated temperatures. Mater Sci Eng A 532: 593-600 (2012)

[40] Karunanithi R, Bera S, Ghosh K S. Electrochemical behaviour of $\mathrm{TiO}_{2}$ reinforced Al 7075 composite. Mater Sci Eng B 190: 133-143 (2014)

[41] Yilmaz S O. Comparison on abrasive wear of $\mathrm{SiCrFe}, \mathrm{CrFeC}$ and $\mathrm{Al}_{2} \mathrm{O}_{3}$ reinforced $\mathrm{A} 12024$ MMCs. Tribol Int 40(3): 441-452 (2007) 
[42] Akbari M K, Mirzaee O, Baharvandi H R. Fabrication and study on mechanical properties and fracture behavior of nanometric $\mathrm{Al}_{2} \mathrm{O}_{3}$ particle-reinforced $\mathrm{A} 356$ composites focusing on the parameters of vortex method. Mater Des, 46 : 199-205 (2013)

[43] Kumar R, Dhiman S. A study of sliding wear behaviors of Al-7075 alloy and Al-7075 hybrid composite by response surface methodology analysis. Mater Des 50: 351-359 (2013)

[44] Sajjadi S A, Parizi M T, Ezatpour H R, Sedghi A. Fabrication of $\mathrm{A} 356$ composite reinforced with micro and nano $\mathrm{Al}_{2} \mathrm{O}_{3}$ particles by a developed compocasting method and study of its properties. J Alloys Compd, 511(1): 226-231 (2012)

[45] Misra A, Finnie I. A classification of three-body abrasive wear and design of a new tester. Wear 60(1): 111-121 (1980)

[46] Baskaran S, Anandakrishnan V, Duraiselvam M. Investigations on dry sliding wear behavior of in situ casted AA7075-TiC metal matrix composites by using Taguchi technique. Mater Des 60: 184-192 (2014)

[47] Siddhartha, Patnaik A, Bhatt A D. Mechanical and dry sliding wear characterization of epoxy- $\mathrm{TiO}_{2}$ particulate filled functionally graded composites materials using Taguchi design of experiment. Mater Des 32(2): 615-627 (2011)

[48] Yunus M, Alsoufi M S. Multi-output optimization of tribological characteristics control factors of thermally sprayed industrial ceramic coatings using hybrid Taguchi-grey relation analysis. Friction 4(3): 208-216 (2016)

[49] Wen J L, Yang Y K, Jeng M C. Optimization of die casting conditions for wear properties of alloy AZ91D components using the Taguchi method and design of experiments analysis. Int J Adv Manuf Technol 41(5-6): 430-439 (2009)

[50] Rohatgi P K, Tabandeh-Khorshid M, Omrani E, Lovell M $\mathrm{R}$, Menezes P L. Tribology of metal matrix composites. In Tribology for Scientists and Engineers. Menezes P L, Nosonovsky M, Ingole S P, Kailas S V, Lovell M R, Eds. New York: Springer, 2013: 233-268.

[51] Kapsiz M, Durat M, Ficici F. Friction and wear studies between cylinder liner and piston ring pair using Taguchi design method. Adv Eng Softw 42(8): 595-603 (2011)

[52] Koksal S, Ficici F, Kayikci R, Savas O. Experimental optimization of dry sliding wear behavior of in situ $\mathrm{AlB}_{2} / \mathrm{Al}$ composite based on Taguchi's method. Mater Des 42: 124-130 (2012)

[53] Sardar S, Karmakar S K, Das D. High stress abrasive wear characteristics of $\mathrm{Al} 7075$ alloy and $7075 / \mathrm{Al}_{2} \mathrm{O}_{3}$ composite. Measurement 127: 42-62 (2018)

[54] Agarwal G, Patnaik A, Sharma R K, Agarwal J. Effect of stacking sequence on physical, mechanical and tribological properties of glass-carbon hybrid composites. Friction 2(4): 354-364 (2014)

[55] Diler E A, Ipek R. Main and interaction effects of matrix particle size, reinforcement particle size and volume fraction on wear characteristics of $\mathrm{Al}-\mathrm{SiC}_{\mathrm{p}}$ composites using central composite design. Compos Part B Eng 50: 371-380 (2013)

[56] Yu S Y, Ishii H, Tohgo K, Cho Y T, Diao D F. Temperature dependence of sliding wear behavior in $\mathrm{SiC}$ whisker or $\mathrm{SiC}$ particulate reinforced 6061 aluminum alloy composite. Wear 213(1-2): 21-28 (1997)

[57] Bowden F P, Tabor D. The Friction and Lubrication of Solids. Oxford (UK): Clarendon Press, 1986.

[58] Hutchings I M, Shipway P H. Tribology: Friction and Wear of Engineering Materials. 2nd ed. Oxford (USA): ButterworthHeinemann, 2017.

[59] Sin H, Saka N, Suh N P. Abrasive wear mechanisms and the grit size effect. Wear 55(1): 163-190 (1979)

[60] Rabinowicz E, Mutis A. Effect of abrasive particle size on wear. Wear 8(5): 381-390 (1965)

[61] Larsen-Badse J. Influence of grit size on the groove formation during sliding abrasion. Wear 11(3): 213-222 (1968)

[62] Richardson R C D. The wear of metals by relatively soft abrasives. Wear 11(4): 245-275 (1968)

[63] Wang A G, Rack H J. Abrasive wear of silicon carbide particulate and whisker-reinforced 7091 aluminum matrix composites. Wear 146(2): 337-348 (1991)

[64] Lee H L, Lu W H, Chan S L I. Abrasive wear of powder metallurgy Al alloy 6061-SiC particle composites. Wear 159(2): 223-231 (1992)

[65] Sardar S, Karmakar S K, Das D. Tribological properties of Al 7075 Alloy and 7075/ $\mathrm{Al}_{2} \mathrm{O}_{3}$ composite under two-body abrasion: A statistical approach. J Tribol, 140(5): 051602 (2018)

[66] Rohatgi P K, Guo R Q, Huang P, Ray S. Friction and abrasion resistance of cast aluminum alloy-fly ash composites. Metall Mater Trans A 28(1): 245-250 (1997)

[67] Zum Gahr K H. Modelling of two-body abrasive wear. Wear 124(1): 87-103 (1988)

[68] Kaushik N C, Rao R N. Influence of applied load on abrasive wear depth of hybrid $\mathrm{Gr} / \mathrm{SiC} / \mathrm{Al}-\mathrm{Mg}-\mathrm{Si}$ composites in a two-body condition. J Tribol 139(6): 061601 (2017)

[69] Modi O P, Yadav R P, Mondal D P, Dasgupta R, Das S, Yegneswaran A H. Abrasive wear behaviour of zincaluminium alloy-10\% $\mathrm{Al}_{2} \mathrm{O}_{3}$ composite through factorial design of experiment. J Mater Sci 36(7): 1601-1607 (2001)

[70] Box G E P, Draper N R. Empirical Model-building and Response Surfaces. New York (USA): Wiley, 1987.

[71] Bradley N. The response surface methodology. Master's thesis. South Bend (USA): Indiana University South Bend, 2007.

[72] Rao C R. Linear Statistical Inference and Its Applications. 2nd ed. New York (USA): Wiley, 1973. 


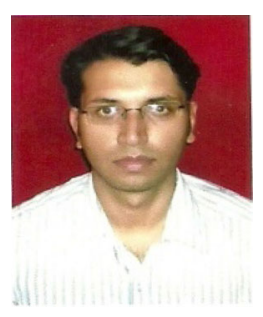

Santanu SARDAR. He is a Ph.D. scholar in the Department of Mechanical Engineering at Indian Institute of Engineering Science and Technology (IIEST), Shibpur, India. He obtained his B.E. degree in mechanical from IIEST Shibpur

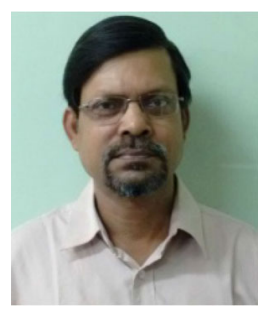

Santanu Kumar KARMAKAR. He obtained his B.E. (mechanical engineering) degree from the B.E. College, Shibpur in 1983 and M.M.E. (production engineering) from Jadavpur University in 1987. He completed his Ph.D. in IIT Delhi in 1993 in the area of tribology. He developed a Stateof-the-Art Advanced Tribology Laboratory with the

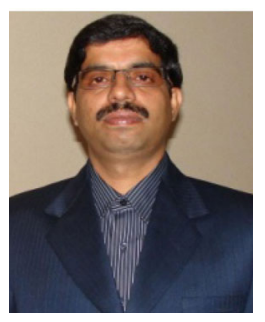

Debdulal DAS. He obtained his B.E. (metallurgy engineering) degree from B.E. College, Shibpur in 1995, M. Tech. (metallurgy) from IIT Kharagpur in 1997 and his Ph.D. from IIEST Shibpur in 2011. He published seventy research articles (formerly, known as B.E. College, Shibpur) and completed his M.Tech. in mechanical engineering from National Institute of Technology, Jamshedpur, India. Prior to joining the Ph.D. program in IIEST Shibpur, he served as a deputy manager in Hindustan Aeronautics Limited (a PSU under Ministry of Defence, India).

aid of DST-FIST Fund of Govt. of India and published several articles in reputed journals. His research area includes micro and bio-tribology, friction and wear modelling, and machine design. He presently holds a professorship position in the Department of Mechanical Engineering in IIEST Shibpur and also serves as the Dean of Alumni Affairs \& External Relations in the same institute.

in archival journals and peer reviewed conference proceedings. His present h-index is 18 . His primary research interest is in the domains of structureproperty correlation, tribology, fatigue, and metal matrix composite. Dr. DAS is presently an associate professor in the Department of Metallurgy and Materials Engineering in IIEST Shibpur, India. 